ARTICLE

Received 22 Jan 2016 | Accepted 5 Sep 2016 | Published 24 Oct 2016

DOI: $10.1038 /$ ncomms13166

OPEN

\title{
Targeted inhibition of the COP9 signalosome for treatment of cancer
}

Anita Schlierf ${ }^{1, \star}$, Eva Altmann ${ }^{1, \star}$, Jean Quancard ${ }^{1}$, Anne B. Jefferson ${ }^{1}{ }^{\dagger}$, René Assenberg ${ }^{1, \dagger}$, Martin Renatus ${ }^{1}$, Matthew Jones ${ }^{1}$, Ulrich Hassiepen ${ }^{1}$, Michael Schaefer ${ }^{1}$, Michael Kiffe ${ }^{1}$, Andreas Weiss ${ }^{1}$, Christian Wiesmann , Richard Sedrani ${ }^{1}$, Jörg Eder ${ }^{1} \&$ Bruno Martoglio ${ }^{1, \dagger}$

The COP9 signalosome (CSN) is a central component of the activation and remodelling cycle of cullin-RING E3 ubiquitin ligases (CRLs), the largest enzyme family of the ubiquitin-proteasome system in humans. CRLs are implicated in the regulation of numerous cellular processes, including cell cycle progression and apoptosis, and aberrant CRL activity is frequently associated with cancer. Remodelling of CRLs is initiated by CSN-catalysed cleavage of the ubiquitin-like activator NEDD8 from CRLs. Here we describe CSN5i-3, a potent, selective and orally available inhibitor of CSN5, the proteolytic subunit of CSN. The compound traps CRLs in the neddylated state, which leads to inactivation of a subset of CRLs by inducing degradation of their substrate recognition module. CSN5i-3 differentially affects the viability of tumour cell lines and suppresses growth of a human xenograft in mice. Our results provide insights into how CSN regulates CRLs and suggest that CSN5 inhibition has potential for anti-tumour therapy.

\footnotetext{
${ }^{1}$ Novartis Institutes for Biomedical Research, Novartis Pharma AG, 4002 Basel, Switzerland. * These authors contributed equally to this work. $\dagger$ Present addresses: Centers for Therapeutic Innovation, Pfizer Inc., San Francisco, California 94158, USA (A.B.J.); Janssen Biologics BV, 2333CB Leiden, The Netherlands (R.A.); Pharma Research \& Early Development, Roche Innovation Center Basel, 4070 Basel, Switzerland (B.M.). Correspondence and requests for materials should be addressed to J.E. (email: joerg.eder@novartis.com) or to E.A. (email: eva.altmann@novartis.com).
} 
T he ubiquitin-proteasome system (UPS) promotes the selective turnover of the majority of regulatory proteins within cells ${ }^{1}$. By a cascade of three enzymatic reactions, individual proteins are tagged with specific types of ubiquitin chains, which serve to direct proteins for degradation by the proteasome $e^{2,3}$. For the assembly of ubiquitin chains on target proteins, ubiquitin is first activated by an E1 ubiquitin-activating enzyme, transferred to an E2 ubiquitin-conjugating enzyme and eventually attached to the target protein by an E3 ubiquitin ligase ${ }^{4-6}$. Many proteins that are regulated by the UPS are central to tumorigenesis and tumour progression, and dysregulation of the UPS is frequently associated with cancer ${ }^{7,8}$. The therapeutic value of drugs targeting the UPS for the treatment of cancer is proven by the success of bortezomib and carfilzomib, which target the system at its very centre by inhibiting the proteolytic activity of the proteasome $\mathrm{e}^{9,10}$. Bortezomib is approved for the treatment of multiple myeloma and mantle cell lymphoma, and carfilzomib for treatment of relapsed or refractory multiple myeloma. However, their use is limited by their narrow therapeutic window due to the broad biological effects seen on general proteasome inhibition ${ }^{11,12}$. One approach to more specifically inhibit the UPS is to target regulatory proteins that modulate UPS activity or interfere with substrate recognition and recruitment ${ }^{13,14}$

E3 ubiquitin ligases define the substrate specificity of the UPS and comprise the largest enzyme family of the system with more than 600 putative members encoded by the human genome ${ }^{15}$. Within this family, cullin-RING E3 ubiquitin ligases (CRLs) are the largest subfamily, responsible for $\sim 20 \%$ of total cellular protein turnover ${ }^{4,16,17}$. CRLs are modular assemblies built around a central cullin scaffold, which associates with an adaptor protein, a substrate receptor module (SRM) and a RING protein that recruits the E2 enzyme ${ }^{18}$ (Fig. 1a). In mammals, about 200 SRMs are available to associate with one of eight cullins to form a CRL specific for a single or small group of substrate proteins ${ }^{19,20}$. Many different CRLs are simultaneously active within a cell at any time and the modular organization allows a dynamic assembly, disassembly and remodelling of CRLs corresponding to the cell's temporal requirements ${ }^{21}$. Critical steps in the cyclic regulation of CRLs are the activation of CRLs induced by the covalent attachment of the ubiquitin-like activator NEDD8 to the cullin moiety and its proteolytic removal leading to deactivation and disassembly $22-24$ (Fig. 1a). CRL neddylation is catalysed by the NEDD8-activating enzyme ${ }^{25}$ (NAE1) and induces a conformational rearrangement that enables the transfer of ubiquitin from the E2 enzyme to the ubiquitin-receiving substrate, which is recruited by the SRM of the respective CRL. The reverse reaction, deneddylation, is catalysed by the COP9 signalosome ${ }^{26-28}$ (CSN) and allows subsequent binding of factors that mediate the disassembly and remodelling of CRL complexes ${ }^{24}$.

The human CSN consists of eight protein subunits (CSN1-8), of which CSN5 contains a JAMM $\mathrm{Zn}^{2+}$-metalloprotease motif that provides the catalytic centre to the complex ${ }^{27,29,30}$. CSN5 exhibits proper deneddylating activity only in the context of the holocomplex and only the fully assembled CSN is competent to specifically remove NEDD8 from CRLs ${ }^{30}$. Multiple studies using RNA interference-induced CSN5 knockdown identified the protease as a positive regulator of oncogenes and negative regulator of tumour suppressors ${ }^{31-34}$. Its role in tumorigenesis is most likely to be indirect via the dysregulation of CRLs and, as a consequence, the disturbed balance of oncogenes and tumour suppressors controlled by CRLs. Furthermore, elevated expression of CSN5 and other CSN subunits is found in a number of human tumours, often correlating with poor prognosis ${ }^{35,36}$. These findings strongly qualify CSN5 as a potential drug target for anti-cancer therapy ${ }^{37}$. In the present study we describe the first selective small molecule inhibitor of CSN5. The compound potently inhibits the deneddylating activity of the CSN. We show how pharmacologic inhibition of CSN modulates CRLs in vitro and demonstrate the potential therapeutic value of an orally available CSN5 inhibitor in a human xenograft model.

\section{Results}

Discovery of selective CSN5 inhibitors. CSN5 is a metalloprotease that exhibits deneddylating activity only in the context of the fully assembled CSN and only against NEDD8-conjugated CRLs $^{30,38}$. Unlike the majority of proteases, it is not active as an individual subunit or as an isolated catalytic domain. Moreover, CSN does not cleave NEDD8-based peptide substrates, different to other deubiquitinating (DUB) enzymes, which typically hydrolyse ubiquitin-conjugated peptides ${ }^{39}$. For the identification of CSN inhibitors, we therefore conducted a high-throughput screening campaign using a biochemical assay with recombinant CSN and a fluorescence-labelled and NEDD8-modified CRL substrate $^{30,40}$ (PT22-NEDD8-SCF ${ }^{\text {Skp2; }}$ S Supplementary Table 1). Among the hits, which included weakly active metal binders like hydroxamates, we selected the tetrahydro-imidazoazepinol CSN5i-1a (Fig. 1b) as a starting point for further optimization, because it also weakly inhibited cullin-1 (Cul1) deneddylation in HCT116 cells as seen in a qualitative western blot analysis (not shown).

In a first round of compound optimization we generated CSN5i-1b (Fig. 1b), which has a slightly improved potency in the biochemical assay (Table 1) and could be co-crystallized with recombinant CSN5. Even though isolated CSN5 is not proteolytically active by itself, its active site appears to be largely intact as seen with the related protease AMSHLP ${ }^{41}$. We therefore speculated that the binding mode of CSN5i-1b to CSN5 resembles, to a significant degree, that of CSN5i-1b to the active CSN complex. The co-crystal structure revealed the imidazole of CSN5i-1b to coordinate the catalytic $\mathrm{Zn}^{2+}$-ion in a monodentate manner and the nitrile to point towards the putative substrate binding cleft (Fig. 1c, red arrow). In addition to the metal coordination, the ligand interacts with the protein predominantly via van der Waals interactions (Supplementary Fig. 1). A weak additional electron density peak in the putative substrate binding cleft close to the ligand nitrile was interpreted as methylpentandiol (MPD), a component of the crystallization buffer. Replacing the nitrile of CSN5i-1b with substituted aminophenyl groups led to compounds that extend into this cleft, for example, CSN5i-2 (Fig. 1b), replacing the MPD molecule, and possess significantly improved potency in biochemical and cellular assays (Table 1 and Supplementary Fig. 2). For further optimization, we focused on improving the pharmacokinetic properties of the compound by replacing the hydrophobic aminophenyl group with more polar heterocyclic moieties. The final compound, CSN5i-3 (Fig. 1b), inhibits CSN-catalysed Cul1 deneddylation with an $\mathrm{IC}_{50}$ value of $5.8 \mathrm{nM}$ and shows a good pharmacokinetic profile (Fig. 1d and Tables 1 and 2).

The crystal structure revealed that the compound retained the binding mode of CSN5i-1b with the substituted pyrazole moiety extending into the hydrophobic channel displacing the buffer molecule. The higher binding affinity seems to be mainly driven by additional hydrophobic interactions with one additional putative hydrogen bond formed between the side chain of Thr154 and the hydrogen atom of the ligand's amide bond. Related JAMM domain containing proteases such as AMSHLP (ref. 41) and RPN11 (ref. 42), and a panel of other metalloproteases were not or only weakly inhibited by the 


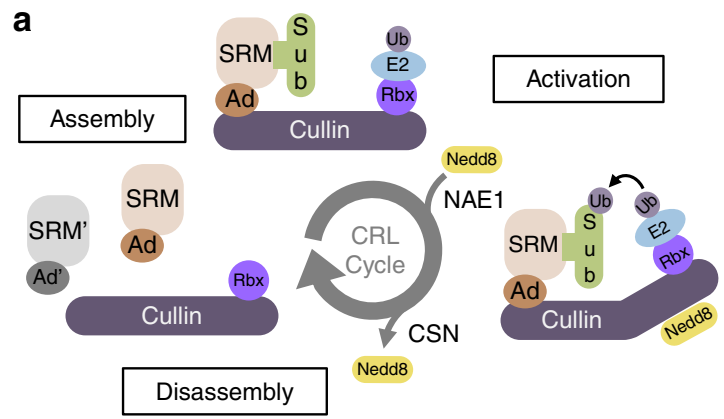

b

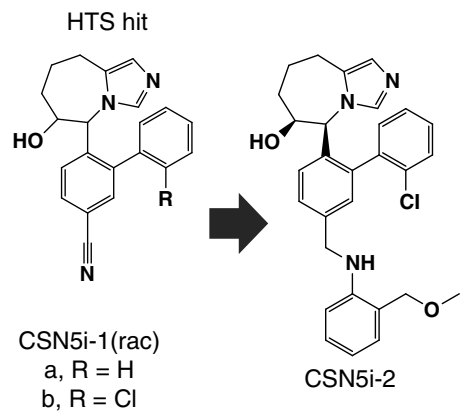

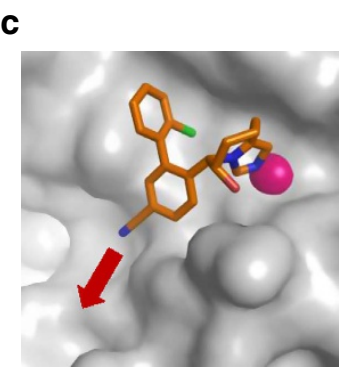

CSN5i-1b

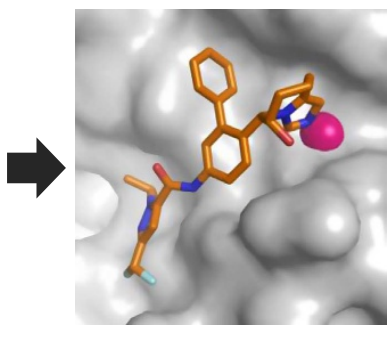

CSN5i-3

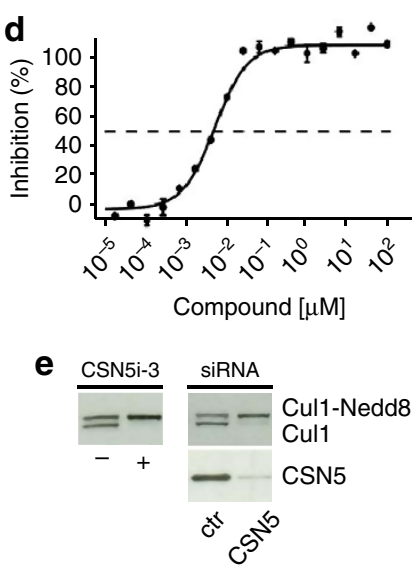

Figure 1 | CSN5i-3 is a potent inhibitor of CSN5-catalysed cullin deneddylation. (a) Schematic illustration of the CRL cycle and the role of cullin neddylation and deneddylation. Ad, adaptor protein; SRM, interchangeable substrate recognition module; Sub, substrate. (b) Chemical structures of CSN5 inhibitors illustrating the optimization of the high throughput screening (HTS) hit CSN5i-1a to the cell active intermediate CSN5i-2, its $R$, R-enantiomer CSN5i-2e and to the final compound CSN5i-3. (c) Co-crystal structures of CSN5 with CSN5i-1b and CSN5i-3. The structures revealed the direction for compound extension into the substrate binding cleft of CSN5 (red arrow). (d) Dose-response curve for inhibition of CSN activity by CSN5i-3 as measured in a biochemical enzyme assay $(n=2, \pm$ s.d.). (e) Immunoblotting for Cul1 after treatment of HCT116 cells with $1 \mu$ M CSN5i-3 and for Cul1 and CSN5 after treatment with CSN5 siRNA.

Table 1 | IC 50 values $[\mu \mathrm{M}]$ of CSN5 inhibitors against JAMM domain proteases and other metalloproteinases.

\begin{tabular}{|c|c|c|c|c|}
\hline Protease & CSN5i-1b & CSN5i-2 & CSN5i-2e & CSN5i-3 \\
\hline $\mathrm{CSN}^{\star}$ & $1.1 \pm 0.5(n=14)$ & $0.002 \pm 0.001(n=2)$ & $2.1 \pm 1.8(n=2)$ & $0.0058 \pm 0.0005(n=5)$ \\
\hline AMSHLP* & $>100$ & $>100$ & $>100$ & $>100$ \\
\hline RPN11* & ND & ND & ND & $53 \pm 26(n=2)$ \\
\hline MMP1 & ND & ND & ND & $>100$ \\
\hline MMP2 & $>100$ & $89 \pm 3(n=2)$ & $\geq 90$ & $>100$ \\
\hline MMP8 & $>100$ & $59 \pm 8(n=2)$ & $48 \pm 8(n=2)$ & $14.0 \pm 0.1(n=2)$ \\
\hline MMP9 & $>100$ & $3.8 \pm 0.4(n=2)$ & $3.2 \pm 0.2(n=2)$ & $7.4 \pm 2.0(n=2)$ \\
\hline MMP12 & $>100$ & $>100$ & $>100$ & $>100$ \\
\hline MMP13 & $>100$ & $>100$ & $>100$ & $>100$ \\
\hline MMP14 & $>100$ & $15.40 \pm 0.02(n=2)$ & $11 \pm 1(n=2)$ & $4.6 \pm 0.5(n=2)$ \\
\hline ADAM17 & $>100$ & $>100$ & $>100$ & $>100$ \\
\hline
\end{tabular}

*JAMM domain proteases.

ND, not determined.

Data are means \pm s.d. of at least two independent experiments. Number of replicates is indicated in brackets.

compound, indicating its excellent selectivity (Table 1). Treatment of cells with CSN5i-3 resulted in the accumulation of neddylated Cul1, similar to the effect seen on CSN5 depletion by small interfering RNA (siRNA) ${ }^{31}$ (Fig. 1e). Moreover, inhibition of CSN5 correlated well with accumulation of neddylated Cul1, and the latter with cell proliferation (see below), for a large number of derivatives of the tetrahydro-imidazoazepinol chemotype (Supplementary Fig. 2), strongly indicating a direct link between CSN5 inhibition and the observed cellular effects. Thus, CSN5i-3 is a potent and selective inhibitor of CSNcatalysed deneddylation of NEDD8-modified CRLs.
Effect of CSN5 inhibition on CRL substrates and SRMs. We first investigated the effect of CSN5 inhibitors on the activation of CRLs in cultured tumour cells and analysed the consequences for CRL substrate turnover. HCT116 cells were treated with either CSN5i-3 or, for comparison, with the NAE1 inhibitor MLN4924 (refs 17,43). The latter inhibitor, which is currently under investigation in phase II clinical trials as anti-cancer agent ${ }^{17,43}$, prevents the neddylation of CRLs and traps them in an inactive state (Figs 1a and 2a,b). As a result, the respective CRL substrates cannot be ubiquitinated and are protected from degradation by the proteasome (Fig. 2c,e,f). Moreover, SRMs, 
Table 2 | CYP3A4 inhibition and key pharmacokinetic parameters in mice of CSN5 inhibitors.

\begin{tabular}{|c|c|c|}
\hline Parameter & CSN5i-2 & CSN5i-3 \\
\hline CYP3A4 $\left(\mathrm{IC}_{50}\right)$ & $<0.5 \mu \mathrm{M}(n=2)$ & $6.8 \pm 1.8 \mu \mathrm{M}(n=2)$ \\
\hline$t_{1 / 2}{ }^{\star}$ & $36 \pm 1 \mathrm{~min}$ & $150 \pm 18 \mathrm{~min}$ \\
\hline $\mathrm{Cl}^{*}$ & $82 \pm 25 \mu \mathrm{lmin}-1 \mathrm{mg}^{-1}$ & $36 \pm 3 \mu \mathrm{lmin}-1 \mathrm{mg}^{-1}$ \\
\hline
\end{tabular}
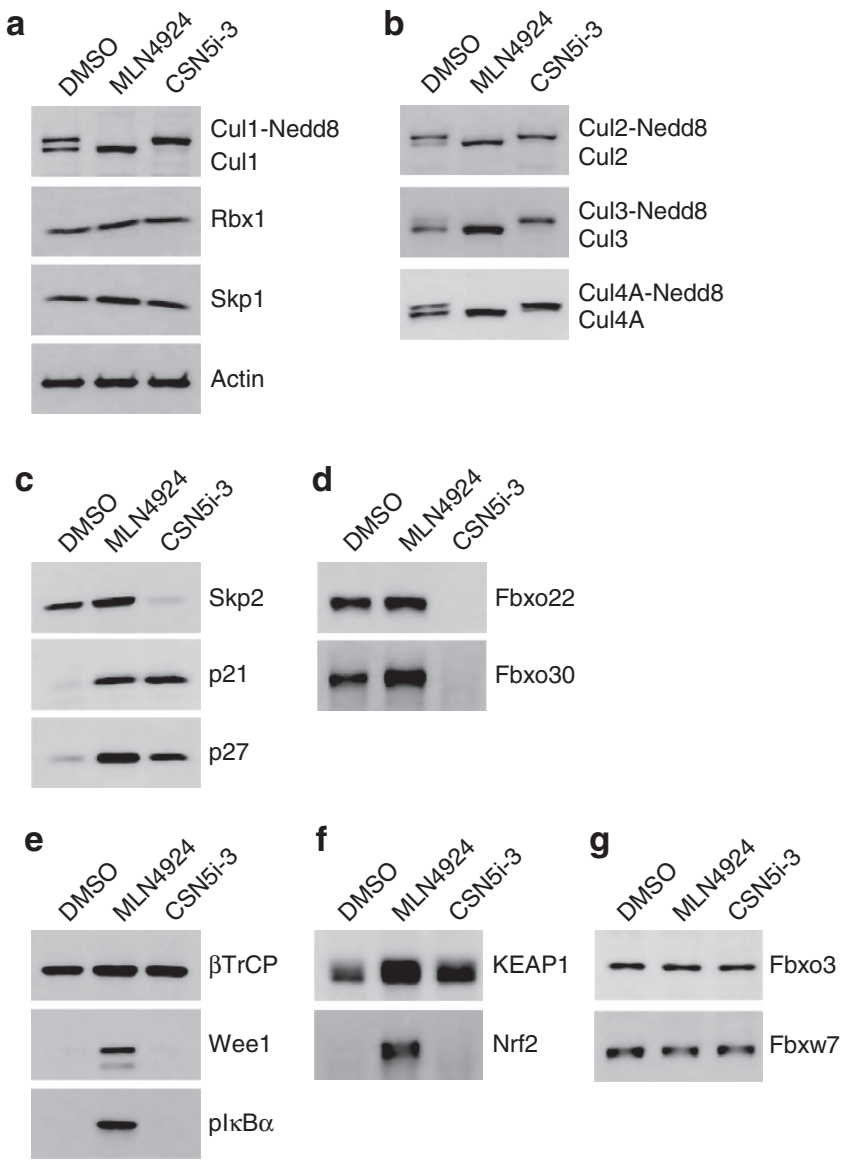

Figure 2 | CSN5 inhibition results in the inactivation of a subset of CRLs and the stabilization of their substrates. Effect on CRL components and substrates after treatment of HCT116 cells with either $1 \mu \mathrm{M}$ MLN4924 or $1 \mu \mathrm{M}$ CSN5i-3. (a) Immunoblottings for Cul1 and its CRL components Rbx and Skp1; (b) for cullins Cul2, Cul3 and Cul4A; (c) for F-box protein Skp2 and the SCF ${ }^{\text {Skp2 }}$ substrates p21 and p27; (d) for F-box proteins Fbxo22 and Fbxo30; (e) for F-box protein $\beta \operatorname{TrCP}$ and the $\mathrm{SCF}^{\beta \operatorname{TrCP}}$ substrates Wee1 and $\operatorname{pl\kappa B} \alpha ;(\mathbf{f})$ for the adaptor KEAP1 and the Cul3 ${ }^{\mathrm{KEAP1}}$ substrate Nrf2; (g) for F-box proteins $\mathrm{Fbxw7}$ and Fbxo3.

which are often auto-ubiquitinated by their respective $\mathrm{CRL}^{44-46}$, are also protected from degradation in the presence of MLN4924 (Fig. 2c-g). In contrast, treatment with CSN5i-3 resulted in the quantitative accumulation of cullins in the neddylated, active state (shown for Cul1, $-2,-3$ and -4 A; Fig. 2a,b) and led to the degradation of SRMs including Skp2, Fbxo22 and Fbxo30 (Fig. 2c,d). Degradation of Skp2 was prevented by pre-incubation with proteasome inhibitors and pre-incubation with MLN4924 prevented Cul1 neddylation as well as Skp2 degradation (Supplementary Fig. 3a), probably indicating an auto-ubiquitination induced mechanism for CRL inactivation
(Supplementary Fig. 3b). The substrates of these CRLs were also protected from degradation as shown for the SCF ${ }^{\text {Skp2 }}$ substrates p21 and p27 (Fig. 2c). MLN4924 and CSN5i-3, therefore, can induce a very similar effect on CRL substrates, albeit through different and opposing mechanisms.

However, not all SRMs were prone to degradation upon CSN5 inhibition. Unlike Skp2, Fbxo22 and Fbxo30, levels of $\beta \operatorname{TrCP}$, KEAP1, Fbxo3 and Fbxw7 remained stable on treatment of HCT116 cells with CSN5i-3 (Fig. $2 \mathrm{e}-\mathrm{g}$ ), and thus the substrates of the corresponding CRLs are affected differently by the two inhibitors. As shown for the SCF ${ }^{\beta T r C P}$ substrates Weel and $\mathrm{pI} \kappa \mathrm{B}$, and the $\mathrm{Cul} 3^{\mathrm{KEAP} 1}$ substrate $\mathrm{Nrf} 2$, treatment with the NAE1 inhibitor prevented the degradation of Wee1, pI $\kappa \mathrm{B}$ and Nrf2, and resulted in their accumulation, whereas treatment with CSN5i-3 did not affect their degradation, which proceeded as in the absence of inhibitor (Fig. 2e,f). This result is consistent with the different mechanistic effects of the two inhibitors with MLN4924 trapping CRLs in the inactive state and CSN5i-3 locking CRLs in the active conformation. Collectively, our data show that the consequences of CSN5 inhibition are distinct from those of NAE1 inhibition (for additional differently affected proteins, see Supplementary Fig. 3c) and indicate that not all SRMs are equally susceptible to CRL-induced auto-ubiquitination and proteasomal degradation.

CSN5 blockade exhibits a differentiating impact on cancer cells. Next, we explored the effect of CSN5 inhibition on the viability of cancer cells. To obtain a comprehensive picture, we generated dose-response curves with a CSN5 inhibitor across more than 500 cancer cell lines in a previously described standardized setting ${ }^{47}$ (Supplementary Data 1). For the study we used CSN5i-2, a CSN5 inhibitor with an almost identical profile to CSN5i-3, but limiting pharmacokinetic parameters, and its poorly active $R, R$-enantiomer CSN5i-2e as a negative control to exclude off-target effects (Fig. 1b, Tables 1 and 2, and Supplementary Fig. 4a). As a benchmark we employed the proteasome inhibitor bortezomib, which is used in the clinic for the treatment of a variety of cancers 9,12 . Bortezomib was universally lethal and provoked cell death $\left(A_{\max }\right.$ of $-95 \%$ to $-100 \%$ ) across all cell lines (Fig. 3a). In contrast, CSN5i-2 was much more variable in its effects on the cell lines tested. Although the compound was cytotoxic to some cell lines to a similar degree as bortezomib $\left(A_{\max } \leq-80 \%\right)$, other cell lines appeared less sensitive to CSN5 inhibition with only a 40-60\% maximal loss of viability (Fig. 3a). The $R, R$-enantiomer CSN5i-2e showed a similar variability in $A_{\max }$ values, yet a much higher compound concentration was required to have an impact on cell growth, reflecting its weaker potency towards CSN5 and excluding major off-target effects of our compounds. Interestingly, conducting analogous dose-response experiments with MLN4924 resulted in a similar overall pattern of cell viability across the panel of cancer cell lines as CSN5i-2 (Supplementary Fig. 4c).

For a selection of cell lines from the cancer cell line panel, we confirmed the differentiating effect of CSN5 inhibition on cell 


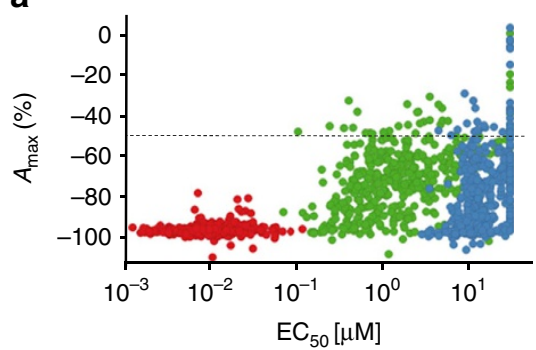

b

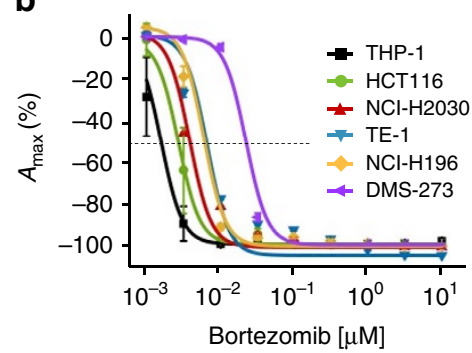

C

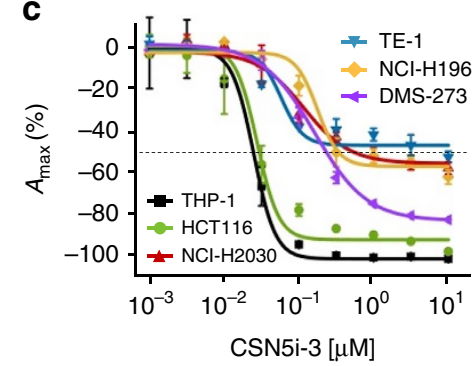

Figure 3 | CSN5 inhibition exhibits a differentiating effect on the viability of cancer cells. (a) Concentration dependent effects of bortezomib (red), CSN5i-2 (green) and CSN5i-2e (blue) on a panel of cancer cell lines. Shown are the high-concentration effect level $\left(A_{\max }\right)$ as derived from the sigmoidal fit of the individual dose-response curves and the corresponding transitional concentration values $\left(E_{50}\right)$. $(\mathbf{b}, \mathbf{c})$ Individual dose response curves of bortezomib and CSN5i-3-treated cell lines $(n=2, \pm$ s.d. $)$.

viability using CSN5i-3. Although bortezomib was again cytotoxic for all cell lines tested $\left(A_{\max } \leq-95 \%\right.$; Fig. 3b), treatment with CSN5i-3 resulted in a differential cell viability pattern as observed with CSN5i-2. To some cell lines, for example, THP-1 and HCT116, the presence of CSN5i-3 was cytotoxic $\left(A_{\max } \leq-95 \%\right)$, whereas to others, for example, NCI-H2030 and TE-1, the CSN5 inhibitor only led to cytostatic effects ( $A_{\max }$ of about $-50 \%$; Fig. $3 \mathrm{c}$ ). These cell line-specific effects were not due to a different degree of CSN5 inhibition, as CSN5i-3 effectively inhibited Cull deneddylation and promoted Skp2 degradation in the cell lines tested, including those in which the CSN5 inhibitor only showed a cytostatic effect (Supplementary Fig. 4b). Therefore, these results indicate a varying dependency of cancer cell lines on CSN5 activity and clearly differentiate CSN5 from proteasome inhibition.

CSN5i-3 inhibits growth of a human xenograft in vivo. When correlating sensitivity to CSN5 inhibition with the genetic background of the tested cancer cell lines ${ }^{47}$, we found that cell lines with CDK6 amplification (JHH-4, NOMO-1, OCI-M1 and SU-DHL-6) were highly sensitive and reached $A_{\max }$ values of $\leq-95 \%$. It is conceivable that the higher sensitivity to CSN5 inhibition of the above cell lines may be explained by the proposed orphan role of the F-box protein $\mathrm{Fbxo7}$ as an enhancer of CDK6 activity ${ }^{48,49}$. Accordingly, Fbxo7 was depleted in, for example, CSN5i-3-treated NOMO-1 cells (Supplementary Fig. 5a). Intrigued by these findings, we selected the anaplastic large-cell lymphoma-derived cell line SU-DHL-1 (ref. 50) for an evaluation of the anti-tumour potential of CSN5i-3 in a xenograft model. For this cell line, a 7q22 amplification combined with CDK6 overexpression was reported ${ }^{51}$. SU-DHL-1 cells were indeed highly sensitive to treatment with CSN5i-3 in vitro with an $\mathrm{EC}_{50}$ value of $0.013 \mu \mathrm{M}$ and $A_{\max } \leq-95 \%$, and Fbxo7 levels were reduced on CSN5 inhibition (Supplementary Fig. 5b). Furthermore, treatment with CSN5i-3 triggered the formation of cleaved PARP and cleaved caspase 3 indicative of apoptosis induction (Supplementary Fig. 5c). For the in vivo study, subcutaneous SU-DHL-1 xenografts were grown in SCID-bg mice and CSN5i-3 was administered orally at doses of $50 \mathrm{mg} \mathrm{kg}^{-1}$ BID and $100 \mathrm{mg} \mathrm{kg}^{-1}$ QD over a period of 14 days. Tumour stasis was achieved with both dosing schemes (Fig. 4a) and inhibition of tumour growth calculated at the last day of treatment reached a T/C value of $22 \%$ (tumour volume of treated versus control samples) for the $50 \mathrm{mg} \mathrm{kg}^{-1}$ BID dose and a T/C value of $25 \%$ for the $100 \mathrm{mg} \mathrm{kg}^{-1}$ QD dose. Tumours were excised at the end of the study and the effect of compound treatment assessed on the pharmacodynamics markers, neddylated Cul1 and Skp2. In line with the anti-tumour efficacy, Cul1 deneddylation was inhibited and Skp2 levels were reduced in the tumours of the treated mice but not in those from vehicle controls (Fig. 4b). A dose-linear exposure was achieved with CSN5i-3 (Fig. 4c) and, based on body weight, both doses were well tolerated (Supplementary Fig. 5d). Based on the CSN5i-3 exposures that were significantly above the $\mathrm{EC}_{50}$ value for inhibition of cell proliferation and between 5 and $10 \mu \mathrm{M}$ at peak and 1 and $2 \mu \mathrm{M}$ at trough, we assume full inhibition of CSN5 over the time course of the experiment.

\section{Discussion}

CSN5i-3 is a potent, selective and orally available inhibitor of the proteolytic subunit CSN5 of the CSN complex. It provides a novel modality by which the UPS can be modulated and differs in its effect from inhibitors of the proteasome. The CSN5 inhibitor interferes with the UPS in a unique manner by enforcing the auto-inactivation of only a subset of CRLs. Therefore, its impact on the UPS is significantly more restricted than that of a proteasome inhibitor, which translated into a strongly differentiating effect on cell growth and cell viability as compared to the treatment with bortezomib. Despite the broad impact on the UPS, bortezomib is successfully used in the clinic for the treatment of multiple myeloma and mantle cell lymphoma ${ }^{52,53}$. Expansion into other cancer indications is, however, hampered by its limited therapeutic window, which is likely to be due to its ubiquitous cytotoxic effects ${ }^{11,12}$. Based on our results, we expect a CSN5 inhibitor to potentially have a larger therapeutic window and to provide new therapeutic opportunities for a number of different cancers.

Our data show that the impact of a CSN5 inhibitor on the UPS is, to some degree, comparable with that of the more recently described NAE1 inhibitor MLN4924 (ref. 17). Promising results have been obtained with this drug candidate in preclinical experiments with various tumour cell lines, as well as with xenograft and transgenic rodent models, and multiple Phase I clinical trials are ongoing ${ }^{43}$. MLN4924 disturbs the UPS less broadly than the proteasome inhibitors, but still affects a wide range of cellular processes, as it prevents the activation of all CRLs and effects other proteins that are regulated by NEDD8 conjugation $^{54}$. The biology of the latter is largely unexplored. The ongoing clinical trials will show whether the more specific impact on the UPS will indeed translate into a good therapeutic window in the clinic. Similarly, a CSN5 inhibitor, which affects only a subset of CRLs as revealed in our study, also modulates the UPS in a more specific manner than proteasome inhibitors. CSN5i-3 had a significantly more differentiating impact on cancer cell lines than bortezomib and thus might have a good prospect for an advantageous clinical profile. However, as we do not yet fully 

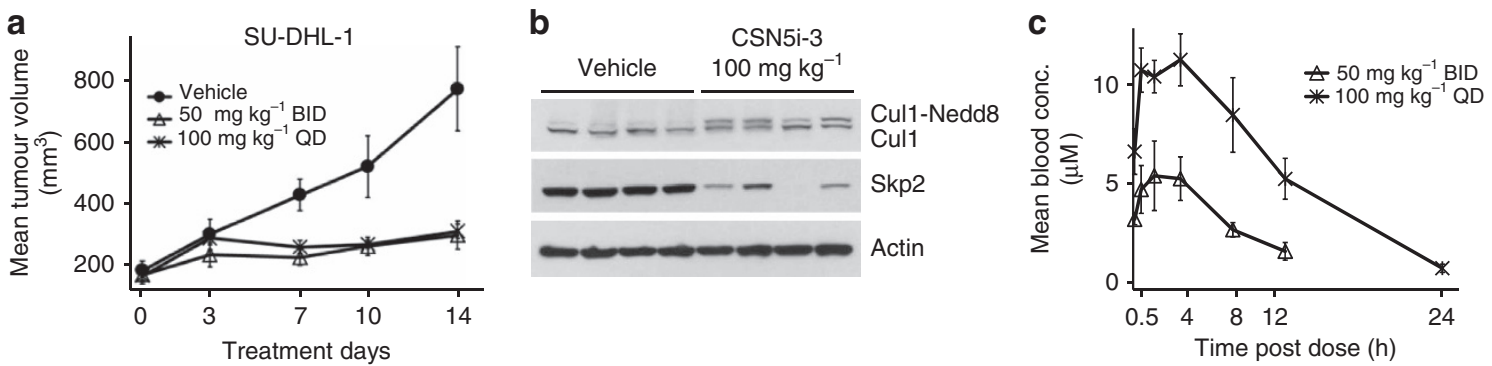

Figure 4 | CSN5i-3 inhibits tumour growth of a human xenograft. (a) SU-DHL-1 xenografts were grown in SCID-bg mice and dosed by oral administration with either vehicle control or CSN5i-3 at the indicated doses and schedules. Mean tumour volumes are shown \pm s.e.m. $(n=4 ; P<0.05)$. (b) Immunoblotting for Cul1 and Skp2 of tumours excised at the end of treatment. (c) Pharmacokinetics of CSN5i-3 post second to last dose. Mean blood concentrations are shown \pm s.e.m. $(n=4)$.

understand the differential dependency of cell lines on CSN5 and how these differences are based on genetic or epigenetic differences, comprehensive studies addressing the effects of CSN5i-3 on oncogenic and tumour suppressive CRLs are critical to facilitate the selection of cancer indications best suited for the treatment with a CSN5 inhibitor. In addition, through further comparative studies it will be interesting to learn more about the similarities and differences of MLN4924 and CSN5i-3 in terms of anti-tumour efficacy and overall clinical profile.

In addition to its therapeutic potential, CSN5i-3 might serve as an important research tool to further study the biology of CRLs and their regulation. For example, its use may facilitate the establishment of a comprehensive overview of SRMs that are regulated by auto-ubiquitination. Moreover, it further enables studying the consequences of modulating the UPS at the level of $\mathrm{CRL}$ assembly and disassembly on the regulation of specific molecular pathways and cellular processes.

To the best of our knowledge, CSN5i-3 is the first potent inhibitor described for the CSN and is the first example of an inhibitor of a JAMM domain-containing DUB enzyme. Our work suggests that this family of DUBs is amenable to the discovery of small molecular weight drugs. The JAMM domain-containing DUB family ${ }^{29}$ may include additional drug targets and the discovery of CSN5 inhibitors can help to find therapeutically relevant antagonists for other family members. One such as yet unexplored drug target might be BRCC36, which, similar to CSN5, acts in the context of an oligomeric complex ${ }^{55}$. In the BRCC36 isopeptidase complex, BRCC36 promotes interferon-dependent responses by deubiquitinating and stabilizing the type I interferon receptor ${ }^{56}$. Moreover, it acts as an activator of the NLRP3 inflammasome by deubiquitinating NLRP3 (ref. 57), thus suggesting its relevance as a potential target for the treatment of autoimmune diseases.

\section{Methods}

Synthesis of CSN5 inhibitors. Reaction schemes for the synthesis of CSN5 inhibitors are illustrated in Supplementary Fig. 6. All commercial reagents and anhydrous solvents were purchased and used without further purification, unless otherwise specified (Supplementary Fig. 6). Reactions were monitored by thin-layer chromatography (TLC), using silica gel $\mathrm{F}_{254}$ glass plates $(5 \times 10 \mathrm{~cm})$ or by ultra performance-liquid chromatography-mass spectrometry (UPLC/MS) or HPLC with ultraviolet detection at 214,220 or $254 \mathrm{~nm}$. Purification was accomplished by flash chromatography using a Combi Flash Rf 200 instrument (Teledyne Isco) and RediSep prepacked silica gel columns. All compounds submitted for biological testing were purified by preparative reversed-phase HPLC using either a Gilson HPLC or a Waters HPLC/MS system using a Waters XBridge Prep C18 OBD column $(5 \mu \mathrm{m}, 30 \times 100 \mathrm{~mm})$. Pure products were lyophilized from acetonitrile (ACN)/ $\mathrm{H}_{2} \mathrm{O}$. Compound purity was determined by UPLC/MS and HPLC as described below. Analytical UPLC/MS analysis was performed on a Waters Acquity UPLC single-stage quadrupole MS (Waters) with electrospray ionization in alternating positive and negative mode. Mass scan range was from 100 to $-1,200 \mathrm{Da}$ in a scan time of $0.3 \mathrm{~s}$ and recorded in centroid mode. Liquid chromatography was performed on an Acquity HSS T3 C18 column $(1.8 \mu \mathrm{m}, 2.1 \times 50 \mathrm{~mm})$ at $60^{\circ} \mathrm{C}$. Solvent A: $0.05 \% \mathrm{HCOOH}, 3.75 \mathrm{mM}$ ammonium acetate in $\mathrm{H}_{2} \mathrm{O}$. Solvent B: $0.04 \%$ $\mathrm{HCOOH}$ in ACN. Flow rate $=1.0 \mathrm{ml} \mathrm{min}^{-1}$. Gradient: $5 \% \rightarrow 98 \% \mathrm{~B}$ in $2 \mathrm{~min}$. Analytical HPLC was performed on an Agilent Series 1200 instrument using a X-Bridge C18 column $(2.5 \mu \mathrm{m}, 3 \times 50 \mathrm{~mm}$; Waters $)$ at $40^{\circ} \mathrm{C}$. Solvent A: $0.1 \%$ trifluoroacetic acid (TFA) in $\mathrm{H}_{2} \mathrm{O}$. Solvent B: $0.1 \%$ TFA in ACN. Flow rate $=1.4$ $\mathrm{ml} \mathrm{min}{ }^{-1}$. Gradient: $10 \% \rightarrow 98 \% \mathrm{~B}$ in $8.6 \mathrm{~min}, 98 \% \rightarrow 98 \% \mathrm{~B}$ in $1.4 \mathrm{~min} .{ }^{1} \mathrm{H}-\mathrm{NMR}$ spectra were recorded on a spectrometer $(400$ or $600 \mathrm{MHz}$; Bruker).

Ethyl 4-(1-trityl-1H-imidazol-4-yl)butanoate 3. To a suspension of 4-iodo-1-trityl-1H-imidazole (2) $(250 \mathrm{~g}, 573 \mathrm{mmol})$ in dry THF (1.2 l) was added $\mathrm{PdCl}_{2}(\mathrm{dppf}) . \mathrm{CH}_{2} \mathrm{Cl}_{2}(46.8 \mathrm{~g}, 57.3 \mathrm{mmol})$ under an argon atmosphere. The reaction mixture was cooled to $0^{\circ} \mathrm{C}$ and a solution of (4-ethoxy-4-oxobutyl)zinc(II)bromide (1) $(0.5 \mathrm{M}$ in THF) $(1.721,860 \mathrm{mmol})$ was added dropwise. Subsequently, the reaction mixture was stirred at $70^{\circ} \mathrm{C}$ for $1.5 \mathrm{~h}$. After cooling to ambient temperature, the reaction was quenched with $\mathrm{H}_{2} \mathrm{O}$ and filtered through a pad of celite. The filtrate was concentrated, the residue was poured into saturated $\mathrm{NaHCO}_{3}$ solution and extracted with EtOAc $(3 \times)$. The combined organic layers were washed with $\mathrm{H}_{2} \mathrm{O}$ and brine, dried over $\mathrm{Na}_{2} \mathrm{SO}_{4}$, filtered, concentrated and the crude residue was purified by flash column chromatography eluting with a gradient of 10 to $100 \%$ EtOAc in hexanes to afford $181.4 \mathrm{~g}(73 \%)$ ethyl 4-(1-trityl-1H-imidazol-4-yl)butanoate (3). UPLC/MS: $R_{\mathrm{t}}=1.10 \mathrm{~min}, 425.3$ $[\mathrm{M}+\mathrm{H}]]^{+} ;{ }^{1} \mathrm{H}-\mathrm{NMR}\left(400 \mathrm{MHz}, \mathrm{DMSO}-d_{6}\right) \delta$ (p.p.m.): 7.46-7.33 (m, 9H), 7.24 $(\mathrm{s}, 1 \mathrm{H}), 7.13-7.03(\mathrm{~m}, 6 \mathrm{H}), 6.54(\mathrm{~s}, 1 \mathrm{H}), 4.06-3.98(\mathrm{q}, J=8 \mathrm{~Hz}, 2 \mathrm{H}), 2.46-2.4$ (m, 2H), 2.3-2.21 (m, 2H), 1.82-1.72 (m, 2H), $1.14(\mathrm{t}, J=8 \mathrm{~Hz}, 3 \mathrm{H})$.

6-Methyl-[1,1'-biphenyl]-3-carbonitrile 6. To a solution of 3-bromo-4methylbenzonitrile (4) $(10 \mathrm{~g}, 51.0 \mathrm{mmol})$ in dimethylformamide $(\mathrm{DMF}) / \mathrm{H}_{2} \mathrm{O}$ $(1: 1,170 \mathrm{ml})$ were added phenylboronic acid (5) $(9.33 \mathrm{~g}, 77 \mathrm{mmol}), \mathrm{Cs}_{2} \mathrm{CO}_{3}$ (24.93 g, $77 \mathrm{mmol})$ and $\mathrm{PdCl}_{2}(\mathrm{dppf}) . \mathrm{CH}_{2} \mathrm{Cl}_{2}(4.17 \mathrm{~g}, 5.10 \mathrm{mmol})$ under an argon atmosphere. The reaction was heated at $90^{\circ} \mathrm{C}$ for $14 \mathrm{~h}$. After cooling to ambient temperature, the reaction was diluted with EtOAc, filtered through a pad of celite and the filtrate was washed with $\mathrm{H}_{2} \mathrm{O}$. The organic layer was dried and concentrated. The crude residue was purified by flash column chromatography eluting with hexanes during $20 \mathrm{~min}$ then with a gradient from 0 to $10 \%$ EtOAc over a period of $30 \mathrm{~min}$ to afford $9.62 \mathrm{~g}$ (97\%) 6-methyl-[1,1'-biphenyl]-3-carbonitrile (6). TLC (hexanes/EtOAc, 9/1 v/v) $R_{\mathrm{F}}=0.43$. UPLC/MS: $R_{\mathrm{t}}=1.20 \mathrm{~min}, 211$ $\left[\mathrm{M}+\mathrm{NH}_{4}\right]^{+}$, HPLC: $R_{\mathrm{t}}=2.57 \mathrm{~min} ;{ }^{1} \mathrm{H}-\mathrm{NMR}\left(400 \mathrm{MHz}, \mathrm{DMSO}-d_{6}\right) \delta$ (p.p.m.): $7.74(\mathrm{dd}, 1 \mathrm{H}, J=7.9,1.8 \mathrm{~Hz}), 7.65(\mathrm{~d}, 1 \mathrm{H}, J=1.8 \mathrm{~Hz}), 7.59-7.32(\mathrm{~m}, 6 \mathrm{H})$, $2.30(\mathrm{~s}, 3 \mathrm{H})$

6-(Bromomethyl)-[1,1'-biphenyl]-3-carbonitrile 7. A solution of 6-methyl[1,1'-biphenyl]-3-carbonitrile (6) (9.62 g, $49.8 \mathrm{mmol})$, NBS (10.63 g, $59.7 \mathrm{mmol})$ and AIBN $(0.817 \mathrm{~g}, 4.98 \mathrm{mmol})$ in $\mathrm{CCl}_{4}(166 \mathrm{ml})$ was heated at $80^{\circ} \mathrm{C}$ for $15 \mathrm{~h}$. After cooling to ambient temperature, the reaction mixture was poured into $\mathrm{H}_{2} \mathrm{O}$ and extracted with dichloromethane $(\mathrm{DCM})(3 \times)$. The combined organic phase was dried, filtered, concentrated and the residue was purified by flash column chromatography eluting with a gradient of 0 to 5\% EtOAc in hexanes to afford $13.2 \mathrm{~g} \mathrm{(68 \% )} \mathrm{6-(bromomethyl)-}$ [1,1'-biphenyl]-3-carbonitrile (7). TLC (hexanes/EtOAc, 9/1 v/v) $R_{\mathrm{F}}=0.39$; UPLC/MS: $R_{\mathrm{t}}=1.21 \mathrm{~min}, 290\left[\mathrm{M}+\mathrm{NH}_{4}\right]^{+}$; HPLC: $R_{\mathrm{t}}=2.64 \mathrm{~min} ;{ }^{1} \mathrm{H}-\mathrm{NMR}(400 \mathrm{MHz}$, DMSO$\left.d_{6}\right) \delta$ (p.p.m.): 7.92-7.70 (m, 3H), 7.57-7.42 (m, 5H), 4.62 (s, $\left.2 \mathrm{H}\right)$.

Ethyl 4-(1-((5-cyano-[1,1'-biphenyl]-2-yl)methyl)-1H-imidazol-5-yl)butanoate 8. To a solution of ethyl 4-(1-trityl-1H-imidazol-4-yl)butanoate (3) (8.97g, $21.13 \mathrm{mmol})$ in acetonitrile $(220 \mathrm{ml})$ was added 6-(bromomethyl)-[1,1'-biphenyl 3 -carbonitrile $(7)(5 \mathrm{~g}, 18.37 \mathrm{mmol})$. The reaction was stirred at ambient temperature for $15 \mathrm{~h}$. Next, the reaction mixture was concentrated, the residue dissolved in $\mathrm{MeOH}(147 \mathrm{ml})$ and stirred at $70{ }^{\circ} \mathrm{C}$ for $3 \mathrm{~h}$. After cooling to ambient temperature, the reaction mixture was concentrated and the residue was purified by flash column chromatography eluting with a gradient of 0 to $10 \%$ EtOAc in hexanes to afford $\mathbf{8}$. Subsequently, product $\mathbf{8}$ was dissolved in EtOAc and washed with saturated $\mathrm{NaHCO}_{3}$ solution $(3 \times)$, the organic phase was dried and concentrated to yield $8.1 \mathrm{~g},(94 \%)$ ethyl 4-(1-((5-cyano-[1,1'-biphenyl]-2-yl) methyl)-1H-imidazol-5-yl)butanoate (8). TLC (hexanes/EtOAc, 9/1 v/v) $R_{\mathrm{F}}=0.45$; UPLC/MS: $R_{\mathrm{t}}=0.81 \mathrm{~min}, 375.0[\mathrm{M}+\mathrm{H}]{ }^{+} ;{ }^{1} \mathrm{H}-\mathrm{NMR}\left(400 \mathrm{MHz}, \mathrm{DMSO}-d_{6}\right) \delta$ 
(p.p.m.): 8.10 (s, 1H), 7.90-7.75 (m, 2H), 7.58-7.38 (m, 5H), 7.10-6.99 (m, 2H), $5.28(\mathrm{~s}, 2 \mathrm{H}), 3.99(\mathrm{q}, J=8 \mathrm{~Hz}, 2 \mathrm{H}), 2.18(\mathrm{t}, 2 \mathrm{H}), 2.16(\mathrm{t}, J=7.2 \mathrm{~Hz}, 2 \mathrm{H}), 1.56$ $(\mathrm{m}, J=7.2 \mathrm{~Hz}, 2 \mathrm{H}), 1.14(\mathrm{t}, J=8 \mathrm{~Hz}, 3 \mathrm{H})$.

6-(6-Oxo-6,7,8,9-tetrahydro-5H-imidazo[1,5-a]azepin-5-yl)-[1,1'-biphenyl]-3carbonitrile 9. A solution of ethyl 4-(1-((5-cyano-[1,1'-biphenyl]-2-yl)methyl)-1Himidazol-5-yl)butanoate $(8)(7.67 \mathrm{~g}, 16.43 \mathrm{mmol})$ in dry THF $(41 \mathrm{ml})$ was degased with argon during $20 \mathrm{~min}$. To this solution was added dropwise over a period of $10 \mathrm{~min}$ a solution of potassium tert-butoxide sublimed grade $(4.06 \mathrm{~g}, 36.1 \mathrm{mmol})$ in dry THF $(41.1 \mathrm{ml})$ under an argon atmosphere. The reaction was stirred for $3 \mathrm{~h}$ at ambient temperature under argon atmosphere. The reaction was quenched with aqueous saturated $\mathrm{NH}_{4} \mathrm{Cl}$ solution and extracted with DCM $(3 \times)$. The organic phase was dried, concentrated and the residue purified by flash column chromatography eluting with a gradient of 0 to $10 \% \mathrm{MeOH}$ in DCM to afford $4.5 \mathrm{~g}$ (84\%) 6-(6-oxo-6,7,8,9-tetrahydro-5H-imidazo[1,5-a]azepin-5-yl)-[1,1'-biphenyl]3-carbonitrile (9). TLC (hexanes/EtOAc, 9/1 v/v) $R_{\mathrm{F}}=0.46$; UPLC/MS: $R_{\mathrm{t}}=0.72 \mathrm{~min}, 328.0[\mathrm{M}+\mathrm{H}]^{+} ;{ }^{1} \mathrm{H}-\mathrm{NMR}\left(400 \mathrm{MHz}, \mathrm{DMSO}-d_{6}\right) \delta$ (p.p.m.): 7.83-7.81 (m, 1H), $7.76(\mathrm{~s}, 1 \mathrm{H}), 7.55(\mathrm{~s}, 1 \mathrm{H}), 7.5-7.01(\mathrm{~m}, 5 \mathrm{H}), 6.86(\mathrm{~m}, 2 \mathrm{H}), 6.29$ (s, 1H), 2.43-2.34 (m, $4 \mathrm{H}), 1.92-1.81(\mathrm{tt}, J=7.1 \mathrm{~Hz}, 2 \mathrm{H})$.

Cis-6-(6-Hydroxy-6,7,8,9-tetrahydro-5H-imidazo[1,5-a]azepin-5-yl)[1,1'-biphenyl]-3-carbonitrile CSN5i-1a. To a solution of 6-(6-oxo-6,7,8,9tetrahydro-5H-imidazo[1,5-a]azepin-5-yl)-[1,1'-biphenyl]-3-carbonitrile (9) $(3.72 \mathrm{~g}, 11.38 \mathrm{mmol})$ in $\mathrm{MeOH}(228 \mathrm{ml})$ at $0{ }^{\circ} \mathrm{C}$ was added $\mathrm{NaBH}_{4}(0.452 \mathrm{~g}$, $11.95 \mathrm{mmol}$ ) in portions. The reaction was stirred at $0{ }^{\circ} \mathrm{C}$ for $1 \mathrm{~h}$ and subsequently quenched with $\mathrm{H}_{2} \mathrm{O}$. MeOH was evaporated and the aqueous phase was extracted with EtOAc $(3 \times)$ and DCM $(2 \times)$. The combined organic layers were dried, concentrated and the residue was purified by flash column chromatography eluting with a gradient of 0 to $10 \% \mathrm{MeOH}$ in DCM, to afford $3.35 \mathrm{~g}$ (94\%) CSN5i-1a. TLC $(\mathrm{DCM} / \mathrm{MeOH}, 9 / 1 \mathrm{v} / \mathrm{v}) R_{\mathrm{F}}=0.33$; UPLC/MS: $R_{\mathrm{t}}=0.70 \mathrm{~min}, 330.1$ $[\mathrm{M}+\mathrm{H}]^{+} ;{ }^{1} \mathrm{H}-\mathrm{NMR}\left(400 \mathrm{MHz}\right.$, DMSO- $\left.d_{6}\right) \delta$ (p.p.m.): $8.45(\mathrm{~d}, J=8.2 \mathrm{~Hz}, 1 \mathrm{H})$, $8.05(\mathrm{dd}, J=8.2,1.7 \mathrm{~Hz}, 1 \mathrm{H}), 7.82(\mathrm{~d}, J=1.7 \mathrm{~Hz}, 1 \mathrm{H}), 7.44-7.30(\mathrm{q}, J=1.7,6.1 \mathrm{~Hz}$, $3 \mathrm{H}), 7.00(\mathrm{~d}, J=6.5 \mathrm{~Hz}, 2 \mathrm{H}), 6.67(\mathrm{~s}, 1 \mathrm{H}), 6.62(\mathrm{~s}, 1 \mathrm{H}), 5.19(\mathrm{~d}, J=4.3 \mathrm{~Hz}, 1 \mathrm{H}), 5.04$ (s, 1H), $4.19(\mathrm{~s}, 1 \mathrm{H}), 2.82-2.75(\mathrm{~d}, \mathrm{~J}=16.4 \mathrm{~Hz}, 1 \mathrm{H}), 2.02-1.06(\mathrm{~d}, J=22.7 \mathrm{~Hz}, 2 \mathrm{H})$, $1.68-1.46(\mathrm{~m}, 3 \mathrm{H})$.

6-(6-Hydroxy-6,7,8,9-tetrahydro-5H-imidazo[1,5-a]azepin-5-yl)-[1,1'-biphenyl]3-carboxylic acid 10. To a solution of 6-(6-hydroxy-6,7,8,9-tetrahydro- $5 \mathrm{H}$ imidazo[1,5-a] azepin-5-yl)-[1,1'-biphenyl]-3-carbonitrile (CSN5i-1a)

$(6 \mathrm{~g}, 18.22 \mathrm{mmol})$ in THF/MeOH $(1: 1 ; 180 \mathrm{ml})$ was added a solution of $\mathrm{NaOH}$ $(10.92 \mathrm{~g}, 274 \mathrm{mmol})$ in $\mathrm{H}_{2} \mathrm{O}(54 \mathrm{ml})$. The reaction mixture was stirred at $60^{\circ} \mathrm{C}$ for $24 \mathrm{~h}$. After cooling to $0^{\circ} \mathrm{C}$ the $\mathrm{pH}$ of the reaction mixture was adjusted to 4.5 by dropwise adding TFA. The reaction was concentrated and the residue was purified by preparative HPLC, solvent $\mathrm{A}: \mathrm{H}_{2} \mathrm{O}+0.1 \%$ TFA, solvent $\mathrm{B}: \mathrm{ACN}+0.1 \%$ TFA, gradient: $5 \rightarrow 100 \% \mathrm{~B}$ in $20 \mathrm{~min}$, flow rate $=40 \mathrm{ml} \mathrm{min}^{-1}$. Pure fractions were combined and lyophilized to afford $6.6 \mathrm{~g}(78 \%)$ of the title compound $\mathbf{1 0}$. UPLC/MS: $R_{\mathrm{t}}=0.61 \mathrm{~min}, 349.2[\mathrm{M}+\mathrm{H}]^{+}$; HPLC: $R_{\mathrm{t}}=1.52 \mathrm{~min} .{ }^{1} \mathrm{H}-\mathrm{NMR}$ $\left(400 \mathrm{MHz}, \mathrm{DMSO}-d_{6}\right) \delta$ (p.p.m.): 13.26 (br s, $\left.1 \mathrm{H}\right), 8.22$ (m, 3H), 7.84 $(\mathrm{d}, \mathrm{J}=1.71 \mathrm{~Hz}, 1 \mathrm{H}), 7.39-7.35(\mathrm{~m}, 4 \mathrm{H}), 7.15(\mathrm{br} \mathrm{s}, 2 \mathrm{H}), 5.52(\mathrm{~s}, 1 \mathrm{H}), 5.51(\mathrm{~m}, 1 \mathrm{H})$, 4.50 (br m, 1H), 2.90 (br dd, $J=14.91,5.84 \mathrm{~Hz}, 1 \mathrm{H}), 2.21-1.40(\mathrm{~m}, 5 \mathrm{H})$.

Tert-butyl((6-((5R,6R)-6-hydroxy-6,7,8,9-tetrahydro-5H-imidazo[1,5-a]azepin5-yl)-[1, $1^{\prime}$-biphenyl]-3-yl)carbamate 11 and tert-butyl((6- $((5 S, 6 S)-6-h y d r o x y-6,7,8$, 9-tetrahydro-5H-imidazo[1,5-a]azepin-5-yl)-[1,1'-biphenyl]-3-yl)carbamate 12. To a solution of 6-(6-hydroxy-6,7,8,9-tetrahydro-5H-imidazo[1,5-a]azepin-5-yl)[1,1'-biphenyl]-3-carboxylic acid (10) $(5.44 \mathrm{~g}, 11.76 \mathrm{mmol})$ and triethylamine (TEA) $(4.1 \mathrm{ml}, 29.4 \mathrm{mmol})$ in THF $(39.2 \mathrm{ml})$ was added diphenyl phosphoryl azide (DPPA) $(2.8 \mathrm{ml}, 12.9 \mathrm{mmol})$. The reaction mixture was stirred at ambient temperature overnight. The reaction was concentrated and the residue dissolved in dry $t$-butanol $(39.2 \mathrm{ml})$ under an argon atmosphere. The reaction was heated at $80^{\circ} \mathrm{C}$ for $3 \mathrm{~h}$. After cooling to ambient temperature, the reaction was concentrated, the residue dissolved in EtOAc and washed with saturated $\mathrm{NaHCO}_{3}$ solution. The aqueous layer was extracted with EtOAc $(3 \times)$. The combined organic layers were dried, filtered, concentrated and purified by flash column chromatography eluting with a gradient of 0 to $10 \% \mathrm{MeOH}$ in DCM to afford $3.38 \mathrm{~g}$ (68\%) tert-butyl(6(6-hydroxy-6,7,8,9-tetrahydro-5H-imidazo[1,5-a] azepin-5-yl)-[1,1'-biphenyl]-3yl)carbamate. Tert-butyl(6-(6-hydroxy-6,7,8,9-tetrahydro-5H-imidazo[1,5a] azepin-5-yl)-[1,1' biphenyl]-3-yl)carbamate was separated into the enantiomers 11 and 12 by preparative chiral HPLC chromatography on a Chiralpak IC column $(20 \mu \mathrm{m}, 500 \times 50 \mathrm{~mm})$ eluting with heptane:DCM:ethanol $(80: 15: 5, \mathrm{v} / \mathrm{v} / \mathrm{v})+0.05 \%$ diethylamine (DEA), flow rate $100 \mathrm{ml} \mathrm{min}^{-1}$, to afford $1.35 \mathrm{~g} \mathrm{(45 \% )} \mathrm{tert-butyl((6-}$ ((5R,6R)-6-hydroxy-6,7,8,9-tetrahydro-5H-imidazo[1,5-a]azepin-5-yl)-[1, ${ }^{\prime}$ biphenyl]-3-yl)carbamate (11) and $1.4 \mathrm{~g}(47 \%)$ tert-butyl((6-((5 S,6 S)-6-hydroxy6,7,8,9-tetrahydro-5H-imidazo[1,5-a]azepin-5-yl)-[1,1'-biphenyl]-3-yl)carbamate (12). UPLC/MS: $R_{\mathrm{t}}=0.93 \mathrm{~min}, 420[\mathrm{M}+\mathrm{H}]^{+}$; HPLC: $R_{\mathrm{t}}=3.91 \mathrm{~min} ;{ }^{1} \mathrm{H}-\mathrm{NMR}$ $\left(400 \mathrm{MHz}, \mathrm{DMSO}-d_{6}\right) \delta$ (p.p.m.): $9.55(\mathrm{~s}, 1 \mathrm{H}), 8.13(\mathrm{~d}, J=8.6 \mathrm{~Hz}, 1 \mathrm{H}), 7.55(\mathrm{dd}$ $J=8.6,2.4 \mathrm{~Hz}, 1 \mathrm{H}), 7.44(\mathrm{~d}, J=2.2 \mathrm{~Hz}, 1 \mathrm{H}), 7.40-7.24(\mathrm{~m}, 3 \mathrm{H}), 7.01-6.85(\mathrm{~m}, 2 \mathrm{H})$, 6.73-6.51 (m, 2H), $5.00(\mathrm{~d}, J=4.1 \mathrm{~Hz}, 1 \mathrm{H}), 4.89(\mathrm{~s}, 1 \mathrm{H}), 4.13-4.08(\mathrm{~d}, J=4.7 \mathrm{~Hz}$, $1 \mathrm{H}), 2.79(\mathrm{~d}, J=15.8 \mathrm{~Hz}, 1 \mathrm{H}), 2.08-1.83(\mathrm{dd}, J=33.0,17.8 \mathrm{~Hz}, 2 \mathrm{H}), 1.54-1.45(\mathrm{~m}$, $3 \mathrm{H}), 1.47(\mathrm{~s}, 9 \mathrm{H})$.

(5S,6S)-5-(5-amino-[1,1'-biphenyl]-2-yl)-6,7,8,9-tetrahydro-5H-imidazo[1,5a]azepin-6-ol 13. To a solution of tert-butyl $(6-((5 \mathrm{~S}, 6 \mathrm{~S})-6$-hydroxy-6,7,8,9tetrahydro-5H-imidazo[1,5-a]azepin-5-yl)-[1,1'-biphenyl]-3-yl)carbamate (12) $(1.4 \mathrm{~g}, 3.34 \mathrm{mmol})$ in dioxane/ $\mathrm{MeOH}(1: 1), 16 \mathrm{ml})$ was added $\mathrm{HCl}(4 \mathrm{M})$ in dioxane $(13.4 \mathrm{ml})$. The reaction mixture was stirred at ambient temperature for $4 \mathrm{~h}$ and concentrated. The residue was purified by preparative HPLC, solvent A: $\mathrm{H}_{2} \mathrm{O}+0.1 \%$ TFA, solvent B: ACN $+0.1 \%$ TFA, gradient: $5 \rightarrow 100 \%$ B in $20 \mathrm{~min}$, flow rate $=40 \mathrm{ml} \mathrm{min}^{-1}$. Pure fractions were combined, saturated $\mathrm{NaHCO}_{3}$ solution was added and the aqueous phase was extracted with DCM $(5 \times)$. The combined organic layers were dried and concentrated to give $1.02 \mathrm{~g}(91 \%)$ of the title compound 13. UPLC/MS: $R_{\mathrm{t}}=0.64 \mathrm{~min}, 320[\mathrm{M}+\mathrm{H}]^{+}$; HPLC: $R_{\mathrm{t}}=1.26 \mathrm{~min} ;{ }^{1} \mathrm{H}-\mathrm{NMR}\left(400 \mathrm{MHz}, \mathrm{DMSO}-d_{6}\right) \delta$ (p.p.m.): $7.91(\mathrm{~d}, J=8.46 \mathrm{~Hz}, 1 \mathrm{H})$, $7.28(\mathrm{~m}, 3 \mathrm{H}), 6.87(\mathrm{~m}, 2 \mathrm{H}), 6.80-6.61(\mathrm{~m}, 2 \mathrm{H}), 6.55(\mathrm{~m}, 1 \mathrm{H}), 6.47(\mathrm{~d}, J=2.42,1 \mathrm{H})$ $5.32(\mathrm{~s}, 2 \mathrm{H}), 4.87(\mathrm{~m}, 1 \mathrm{H}), 4.79(\mathrm{~s}, 1 \mathrm{H}), 4.11(\mathrm{~m}, 1 \mathrm{H}), 2.79(\mathrm{br} \mathrm{d}, J=14.41 \mathrm{~Hz}, 1 \mathrm{H})$ 2.06-1.82 (m, 2H), 1.68-1.37 (m, 3H).

Ethyl 3-(difluoromethyl)-1-isopropyl-1H-pyrazole-5-carboxylate 15. To a solution of ethyl 3-(difluoromethyl)-1H-pyrazole-5-carboxylate (14) (1 g, $5.2 \mathrm{mmol}$ ) in dry dimethylformamide (DMF) $(20 \mathrm{ml})$ under an argon atmosphere was added $\mathrm{K}_{2} \mathrm{CO}_{3}(1.8 \mathrm{~g}, 13.15 \mathrm{mmol})$. The reaction was stirred at ambient temperature for $10 \mathrm{~min}$ then 2-iodopropane $(550 \mu \mathrm{l}, 5.2 \mathrm{mmol}$ ) was added and the mixture was stirred at $40{ }^{\circ} \mathrm{C}$ for $3 \mathrm{~h}$. After cooling to ambient temperature, $\mathrm{H}_{2} \mathrm{O}$ was added and the mixture was extracted with EtOAc $(3 \times)$. The combined organic phase was dried, concentrated and the residue was purified by flash column chromatography eluting with a gradient of 0 to $50 \%$ EtOAc in hexanes to afford $0.940 \mathrm{~g}(75 \%)$ 15. TLC (hexanes/EtOAc, $8: 2 \mathrm{v} / \mathrm{v}$ ) $R_{\mathrm{F}}=0.61$; UPLC/MS: $R_{\mathrm{t}}=1.13 \mathrm{~min}, 233.1[\mathrm{M}+\mathrm{H}]^{+}$; HPLC: $R_{\mathrm{t}}=2.47 \mathrm{~min} ;{ }^{1} \mathrm{H}-\mathrm{NMR}(400 \mathrm{MHz}$, DMSO- $\left.d_{6}\right) \delta$ (p.p.m.): 7.27-6.89 (m, 2H), $5.46(\mathrm{~m}, J=6.8 \mathrm{~Hz}, 1 \mathrm{H}), 4.33(\mathrm{q}$, $J=7.9 \mathrm{~Hz}, 2 \mathrm{H}), 1.44(\mathrm{dd}, J=6.8 \mathrm{~Hz}, 6 \mathrm{H}), 1.33(\mathrm{t}, J=7.9 \mathrm{~Hz} 3 \mathrm{H})$.

3-(Difluoromethyl)-1-isopropyl-1H-pyrazole-5-carboxylic acid 16. To a solution of ethyl 3-(difluoromethyl)-1-isopropyl-1H-pyrazole-5-carboxylate (15) $(900 \mathrm{mg}$, $0.38 \mathrm{mmol})$ in $\mathrm{THF} / \mathrm{H}_{2} \mathrm{O} / \mathrm{MeOH}(1: 1: 1,18 \mathrm{ml})$ was added $\mathrm{LiOH}_{2} \mathrm{H}_{2} \mathrm{O}(162 \mathrm{mg}$, $0.38 \mathrm{mmol}$ ). The reaction mixture was stirred at ambient temperature for $4 \mathrm{~h}$ and the reaction was concentrated. The residue was taken up in $\mathrm{HCl}(1 \mathrm{~N})$ and extracted with EtOAc $(3 \times)$. The combined organic layers were dried and concentrated. The title compound $160.77 \mathrm{~g}(99 \%)$ was used without further purification. UPLC/MS: $R_{\mathrm{t}}=0.72 \mathrm{~min}, 205[\mathrm{M}+\mathrm{H}]^{+}$; HPLC: $R_{\mathrm{t}}=1.78 \mathrm{~min}$; ${ }^{1} \mathrm{H}-\mathrm{NMR}\left(400 \mathrm{MHz}, \mathrm{DMSO}-d_{6}\right) \delta$ (p.p.m.): 13.98 (br s, $\left.1 \mathrm{H}\right), 7.32-6.79(\mathrm{~m}, 2 \mathrm{H})$, $5.52(\mathrm{qq}, J=6.9 \mathrm{~Hz}, 1 \mathrm{H}), 1.42(\mathrm{~d}, J=6.9 \mathrm{~Hz}, 6 \mathrm{H})$.

3-(Difluoromethyl)-N-(6-((5S,6S)-6-hydroxy-6,7,8,9-tetrahydro-5H-imidazo [1,5-a]azepin-5-yl)-[1,1'-biphenyl]-3-yl)-1-isopropyl-1H-pyrazole-5-carboxamide CSN5i-3. To a solution of (5 S,6S)-5-(5-amino-[1,1'-biphenyl]-2-yl)-6,7,8,9tetrahydro-5H-imidazo[1,5-a]azepin-6-ol (13) $(1.0 \mathrm{~g}, 3.13 \mathrm{mmol})$ in DCM $(18 \mathrm{ml})$ was added 3-(difluoromethyl)-1-isopropyl-1H-pyrazole-5-carboxylic acid (16) $(0.77 \mathrm{~g}, 3.76 \mathrm{mmol}), \mathrm{N}, \mathrm{N}$-diisopropylethylamine (DIPEA) $(2.3 \mathrm{ml}, 4 \mathrm{mmol})$ and propylphosphonic anhydride (T3P) $(1.6 \mathrm{ml}, 9.3 \mathrm{mmol})$. The reaction was stirred at ambient temperature for $2 \mathrm{~h}$, subsequently concentrated and the residue was purified by preparative HPLC, solvent $\mathrm{A}: \mathrm{H}_{2} \mathrm{O}+7.3 \mathrm{mM} \mathrm{NH}_{4} \mathrm{OH}$, solvent $\mathrm{B}$ : $\mathrm{ACN}+7.3 \mathrm{mM} \mathrm{NH} \mathrm{H}_{4} \mathrm{OH}$, gradient: $5 \rightarrow 99 \% \mathrm{~B}$ in $12.5 \mathrm{~min}$ and $99 \% \mathrm{~B}$ maintained for $2.5 \mathrm{~min}$, flow rate $=45 \mathrm{ml} \mathrm{min}^{-1}$. Pure fractions were combined and lyophilized to afford $1.2 \mathrm{~g}(74 \%)$ CSN5i-3. UPLC/MS: $R_{\mathrm{t}}=0.91 \mathrm{~min}, 506.4$ $[\mathrm{M}+\mathrm{H}]^{+}$; HPLC; $R_{\mathrm{t}}=4.29 \mathrm{~min} .{ }^{1} \mathrm{H}-\mathrm{NMR}\left(600 \mathrm{MHz}\right.$, DMSO- $\left.d_{6}\right) \delta$ (p.p.m.): 10.59 $(\mathrm{s}, 1 \mathrm{H}), 8.28(\mathrm{~d}, J=8.6 \mathrm{~Hz}, 1 \mathrm{H}), 7.90(\mathrm{dd}, J=8.6,1.9 \mathrm{~Hz}, 1 \mathrm{H}), 7.80(\mathrm{~d}, J=1.8 \mathrm{~Hz}$, $1 \mathrm{H}), 7.41-7.24(\mathrm{~m}, 4 \mathrm{H}), 7.10(\mathrm{t}, J=54.6 \mathrm{~Hz}, 1 \mathrm{H}), 6.98(\mathrm{~d}, J=5.7 \mathrm{~Hz}, 2 \mathrm{H}), 6.73$ $(\mathrm{s}, 1 \mathrm{H}), 6.61(\mathrm{~s}, 1 \mathrm{H}), 5.44(\mathrm{p}, J=6.6 \mathrm{~Hz}, 1 \mathrm{H}), 5.14(\mathrm{~d}, J=3.6 \mathrm{~Hz}, 1 \mathrm{H}), 4.99(\mathrm{~s}, 1 \mathrm{H})$, $4.20(\mathrm{~s}, 1 \mathrm{H}), 2.82(\mathrm{~d}, J=15.2 \mathrm{~Hz}, 1 \mathrm{H}), 2.03(\mathrm{dt}, J=14.2,6.9 \mathrm{~Hz}, 1 \mathrm{H}), 2.00-1.89(\mathrm{~m}$, $1 \mathrm{H}), 1.66-1.49(\mathrm{~m}, 3 \mathrm{H}), 1.44(\mathrm{~d}, J=6.6 \mathrm{~Hz}, 6 \mathrm{H})$. HRMS $(\mathrm{m} / \mathrm{z})[\mathrm{M}+\mathrm{H}]^{+}$calcd for C28H29N5O2F2 506.2362, found 506.2362.

(5S,6S)-5-(2'-chloro-5-(((2-(methoxymethyl)phenyl)amino)methyl)[1,1'-biphenyl]-2-yl)-6,7,8,9-tetrahydro-5H-imidazo[1,5-a]azepin-6-ol CSN5i-2 and $(5 R, 6 R)-5-\left(2^{\prime}-\right.$ chloro-5-((2-(methoxymethyl) phenyl)amino)methyl)-

[1,1'-biphenyl]-2-yl)-6,7,8,9-tetrahydro-5H-imidazo[1,5-a]azepin-6-ol CSN5i-2e. Compounds were prepared in analogy to the synthesis described for CSN5i-3. CSN5i-2; UPLC/MS: $R_{\mathrm{t}}=0.97$ and $1.00 \mathrm{~min}$ (atropisomers), $488[\mathrm{M}+\mathrm{H}]^{+}$; HPLC: $R_{\mathrm{t}}=4.10$ and $4.27 \mathrm{~min}$ (atropisomers); ${ }^{1} \mathrm{H}-\mathrm{NMR}\left(400 \mathrm{MHz}, \mathrm{DMSO}-\mathrm{d}_{6}\right)$ $\delta$ (p.p.m.): 8.21 and $8.11(\mathrm{~d}, J=8.16 \mathrm{~Hz}, 1 \mathrm{H}), 7.56(\mathrm{~m}, 2 \mathrm{H}), 7.38(\mathrm{~m}, 2 \mathrm{H}), 7.13$ (m, 4H), $6.62(\mathrm{~m}, 4 \mathrm{H}), 5.71(\mathrm{~m}, 1 \mathrm{H}), 5.05(\mathrm{~m}, 1 \mathrm{H}), 4.47-4.15(\mathrm{~m}, 5 \mathrm{H}), 3.26(\mathrm{~s}, 3 \mathrm{H})$, $2.73(\mathrm{~m}, 1 \mathrm{H}), 2.43(\mathrm{~m}, 1 \mathrm{H}), 2.01-1.26(\mathrm{~m}, 5 \mathrm{H})$. HRMS $(\mathrm{m} / \mathrm{z})[\mathrm{M}+\mathrm{H}]^{+}$calcd for C29H30ClN3O2 488.2099, found 488.2099. CSN5i-2e; UPLC/MS: $R_{\mathrm{t}}=0.98$ and $1.00 \mathrm{~min}$ (atropisomers), $488[\mathrm{M}+\mathrm{H}]^{+}$; HPLC: $R_{\mathrm{t}}=4.11$ and $4.28 \mathrm{~min}$ (atropisomers); ${ }^{1} \mathrm{H}-\mathrm{NMR}\left(400 \mathrm{MHz}, \mathrm{DMSO}-\mathrm{d}_{6}\right) \delta$ (p.p.m.): 8.21 and 8.11 $(\mathrm{d}, J=8.16 \mathrm{~Hz}, 1 \mathrm{H}), 7.56(\mathrm{~m}, 2 \mathrm{H}), 7.39(\mathrm{~m}, 2 \mathrm{H}), 7.13(\mathrm{~m}, 4 \mathrm{H}), 6.76-6.52(\mathrm{~m}, 4 \mathrm{H})$, $5.73(\mathrm{~m}, 1 \mathrm{H}), 5.06(\mathrm{~m}, 1 \mathrm{H}), 4.67(\mathrm{~s}, 1 \mathrm{H}), 4.48-4.25(\mathrm{~m}, 4 \mathrm{H}), 3.25(\mathrm{~s}, 3 \mathrm{H}), 2.74$ (m, $1 \mathrm{H}), 2.16-1.84(\mathrm{~m}, 2 \mathrm{H}), 1.59-1.25(\mathrm{~m}, 3 \mathrm{H})$. HRMS $(\mathrm{m} / \mathrm{z})[\mathrm{M}+\mathrm{H}]^{+}$calcd for C29H30ClN3O2 488.2099, found 488.2097.

\section{Co-crystal structures of CSN5 with CSN5i-1b and CSN5i-3. Human CSN5} (2-257) was expressed in Escherichia coli with an amino-terminal His 6 tag and a Tobacco etch virus (TEV) protease cleavage site. In brief, expression from pET-28b vector in E. coli grown in lysogeny broth (LB) media was induced by the addition of $0.1 \mathrm{mM}$ isopropyl- $\beta$-D-thiogalactoside at $\mathrm{OD}_{600} 0.5$ and expression continued for $16 \mathrm{~h}$ at $20^{\circ} \mathrm{C}$. Pelleted cells were resuspended in $50 \mathrm{mM}$ Tris- $\mathrm{HCl} \mathrm{pH} 8,200 \mathrm{mM}$ $\mathrm{NaCl}$ and $20 \mathrm{U} \mathrm{ml}^{-1}$ Benzoase Nuclease (Merck), frozen and subsequently homogenized in the presence of protease inhibitors AEBSF and Complete EDTAfree inhibitor cocktail (Roche) using a French Press. Filtered cell lysates were purified on an IMAC column ( $10 \mathrm{ml}$ bedvolume, Ni-NTA Superflow; Qiagen) 
attached to an Aekta Explorer FPLC system (GE Healthcare). CSN5(2-257) containing fractions were concentrated, treated with Tobacco etch virus (TEV) protease (Promega) and applied to a size-exclusion chromatography column (Superdex 75, HiLoad 26/60; GE Healthcare), and eluted in $25 \mathrm{mM}$ MES-Na pH $6.0,50 \mathrm{mM} \mathrm{NaCl}$ and $1 \mathrm{mM}$ tris(2-carboxyethyl)phosphine (TCEP). The protein was concentrated $25 \mathrm{mg} \mathrm{ml}^{-1}$ and flash cooled in liquid nitrogen.

Crystals of CSN5(2-257) were obtained under several conditions using commercially available crystallization solutions, for example, JCSG-Core I suite condition F12, $0.1 \mathrm{M}$ phosphate citrate $\mathrm{pH} 4.2$ with 40\% MPD (Molecular Dimensions), but only in the presence of ligand and additional amounts of zinc ions. They were subsequently improved by crystal seeding. In the final procedure, $0.3 \mu \mathrm{l}$ of CSN5(2-257) at a concentration of $15 \mathrm{mg} \mathrm{ml}^{-1}$ in $50 \mathrm{mM} \mathrm{NaCl}, 50 \mathrm{mM}$ $\mathrm{MES} / \mathrm{NaOH}$ at $\mathrm{pH} 6.0,1 \mathrm{mM}$ TCEP, $1 \mathrm{mM} \mathrm{CSN5i-1b}$ and $10 \mu \mathrm{M} \mathrm{ZnCl}_{2}$ were mixed with $0.3 \mu \mathrm{l}$ crystallization solution and $0.1 \mu \mathrm{l}$ of seed solution in a 96-well Intelli crystallization plate (Hampton Research) and equilibrated at room temperature against 35\% MPD, 0.2 M lithium sulfate and $0.1 \mathrm{M} \mathrm{MES} / \mathrm{NaOH}$ at $\mathrm{pH}$ 6.0. For diffraction experiments, the crystals were mounted from mother liquor and flash-cooled without the addition of additional cryo-protectant. Diffraction data were collected at the Swiss Light Source beamline X10SA (Swiss Light Source, Paul Scherrer Institute, Switzerland) equipped with a Pilatus Pixel Detector (Dectris, Switzerland). The CSN5(2-257)-CSN5i-3 complex was obtained by using crystals grown in the presence of CSN5i-1a and subsequent back-soaked with $10 \mathrm{mM}$ CSN5i-3 overnight. All crystallographic data were processed with XDS/XSCALE as part of the APRV package ${ }^{58}$. The CSN5(2-257)-CSN5i-1b structure was solved using phaser ${ }^{59}$ and $4 \mathrm{f} 7 \mathrm{o}$ as search model ${ }^{60}$. Coot $^{61}$ was used for visual inspection and models were refined with autoBuster (BUSTER version 2.11.5; Global Phasing Ltd). All structure figures were generated using pymol (The PyMOL Molecular Graphics System version 1.5.0.4; Schrödinger LLC). Data collection and structure refinement statistics are summarized in Supplementary Table 2.

Protein expression and purification. CSN and Cul4A-Rbx1-DDB1-DDB2 complexes were expressed in Sf21 cells by co-infection of separate baculoviruses as previously described ${ }^{30}$. The cells were lysed by sonication, followed by centrifugation at $50,000 \mathrm{~g}$ for $50 \mathrm{~min}$ at $4{ }^{\circ} \mathrm{C}$. Ni-sepharose FastFlow resin (GE Healthcare) was added to the cleared supernatant for batch purification. The eluted protein was dialysed against buffer A $(20 \mathrm{mM}$ Tris- $\mathrm{HCl} \mathrm{pH} 8$ and $1 \mathrm{mM}$ dithiothreitol (DTT)) and applied to a Source Q ion-exchange chromatography column (GE Healthcare) equilibrated in buffer A. A NaCl gradient of $0-1 \mathrm{M} \mathrm{NaCl}$ was applied and protein containing fractions harvested, concentrated and stored at $-80^{\circ} \mathrm{C}$ before further use.

The purified Cul4A complex was next enzymatically modified with PT22-lablelled NEDD8. The required E1 and E2 enzymes for neddyation (UBA3/NEA1 complex and UBC12) were expressed in $E$. coli with N-terminal HRV 3C protease cleavable extensions ( $\mathrm{His}_{6}-\mathrm{ZZ}-3 \mathrm{C}$ for NAE1, $\mathrm{His}_{6}$-thioredoxin-S tag-3C for UBC12 and His $_{6}-$ ZZ-3C-Cys for NEDD8 (ref. 40)). Proteins were affinity purified using Ni-sepharose FastFlow resin (GE Healthcare) followed by protease tag removal and size-exclusion chromatography in $50 \mathrm{mM}$ Tris- $\mathrm{HCl}$ $\mathrm{pH} 7.4,150 \mathrm{mM} \mathrm{NaCl}, 10 \%$ glycerol for UBA3/NAE1 and Cys-NEDD8, or $25 \mathrm{mM}$ Tris- $\mathrm{HCl} \mathrm{pH} 7.5,50 \mathrm{mM} \mathrm{NaCl}, 5 \mathrm{mM} \mathrm{MgCl}$ and $0.25 \mathrm{mM}$ DTT for UBC12. Cys-NEDD8 was next labelled in the dark under argon with PT-22 maleimide (AssayMetrics) in $50 \mathrm{mM}$ Tris $\mathrm{pH} 7.5,150 \mathrm{mM} \mathrm{NaCl}, 0.5 \mathrm{mM}$ TCEP and $10 \%$ glycerol using a $5 \times$ molar excess of PT22. For subsequent neddylation of the Cul4A complex, UBA3/NAE1, UBC12, PT22-labelled NEDD8 and Cul4A complex were mixed at $0.5,0.5,10$ and $4 \mu \mathrm{M}$ final concentration, respectively, in $50 \mathrm{mM}$ Tris- $\mathrm{HCl} \mathrm{pH} 7.5,100 \mathrm{mM} \mathrm{NaCl}, 12.5 \mathrm{mM}$ ATP, $0.5 \mathrm{mM}$ DTT and $2.5 \mathrm{mM}$ $\mathrm{MgCl}_{2}$. The solution was incubated for $2 \mathrm{~h}$ at room temperature and then purified on a HiLoad 16/60 Superdex 200 size-exclusion chromatography column equilibrated in $50 \mathrm{mM}$ Tris $\mathrm{pH} 7.5,100 \mathrm{mM} \mathrm{NaCl}, 0.05 \%$ CHAPS and $1 \mathrm{mM}$ DTT.

CSN5 activity assay. The potency of CSN5 inhibitors was determined in a CSN activity assay using changes in fluorescence polarization as the readout ${ }^{30}$. Reactions were carried out at room temperature in 384-well plates. Stock solutions (10 mM) of test compound in dimethyl sulfoxide (DMSO) were pre-diluted in $90 \%$ (v/v) $\mathrm{DMSO} /$ water to 101 times the desired assay concentration. Compound solution $(0.25 \mu \mathrm{l})$ was then added per well, followed by the addition of $12.5 \mu \mathrm{l} \mathrm{CSN}$ solution ( $150 \mathrm{pM}$ final assay concentration). After $1 \mathrm{~h}$ pre-incubation, the reaction was started by the addition of $12.5 \mu \mathrm{l}$ PT22-Nedd8-Cul4A complex solution (150 nM final assay concentration) and allowed to progress for $1 \mathrm{~h}$. The effect of compound on enzymatic activity was determined from the linear part of the progression curves by an end-point measurement of the fluorescence polarization at $590 \mathrm{~nm}$ after excitation at $540 \mathrm{~nm}$ using a PHERAstar plate reader (BMG LABTECH $\mathrm{GmbH}) . \mathrm{IC}_{50}$ values were calculated from the plot of percentage of inhibition versus inhibitor concentration using the non-linear regression analysis software Origin 7.5SR6 (OriginLab Corp.).

Selectivity assays. All biochemical assays were performed at room temperature in 384 -well plates in a total volume of $25.25 \mu \mathrm{l}$ per well. Test compounds were dissolved in $90 \%$ (v/v) DMSO/water. For the assays, $250 \mathrm{nl}$ of compound solution was added per well, followed by addition of $12.5 \mu \mathrm{l}$ protease solution. After $70 \mathrm{~min}$ of pre-incubation at room temperature, the reactions were started by addition of $12.5 \mu \mathrm{l}$ substrate solution and followed either by measuring fluorescence intensity (rhodamine 110-based substrates) or by fluorescence lifetime (PT14-based substrates). The effect of compound on enzymatic activity was obtained from the linear part of the progress curves and determined after $1 \mathrm{~h}(t=60 \mathrm{~min})$. The final compound concentrations ranged from $100 \mu \mathrm{M}$ to $1 \mathrm{nM}$.

RPN11 (26S proteasome). Enzyme purchased from LifeSensors (catalogue number PS026); substrate: K48-linked tetra-ubiquitin chain coupled to a rhodamine 110 fluorophore purchased from LifeSensors (catalogue number NO13-158.01); enzyme concentration: $0.75 \mathrm{nM}$; substrate concentration: $100 \mathrm{nM}$; assay buffer: $20 \mathrm{mM}$ Hepes at $\mathrm{pH} 7.4,150 \mathrm{mM} \mathrm{NaCl}, 0.02 \%$ Tween-20, $0.5 \mathrm{mM}$ TCEP, $0.05 \mathrm{mM} \mathrm{MgCl}_{2}, 1 \mathrm{mM}$ ATP and $2 \mu \mathrm{M}$ ubiquitin aldehyde.

Human AMSHLP. Enzyme was expressed in and purified from E. coli; substrate: ubiquitin-rhodamine110-glycine was purchased from emp Biotech $\mathrm{GmbH}$ (Berlin Germany; product number AS 09/12-A4); enzyme concentration: $4 \mathrm{nM}$; substrate concentration: $200 \mathrm{nM}$; assay buffer: $100 \mathrm{mM}$

Tris/ $\mathrm{HCl}$ at $\mathrm{pH} 7.5,10 \mathrm{mM} \mathrm{CaCl}_{2}, 100 \mathrm{mM} \mathrm{NaCl}, 10 \mu \mathrm{M} \mathrm{ZnCl}_{2}, 0.005 \%$ (v/v) BRIJ 35 and $5 \mathrm{mM}$ dithioerythritol (DTE).

Matrix metalloproteinases. Human MMP1 (Uniprot P03956), amino acids 1-469, expressed in and purified from stable transfected C127 cells; human MMP2 (Uniprot P08253), amino acids 1-660, expressed in and purified from insect cells (baculovirus expression system); human MMP8 (Uniprot P22894), amino acids 100-262, expressed in and purified from E. coli; human MMP9 (Uniprot P14780), amino acids 1-707, expressed in and purified from stable transfected 293 cells; human MMP12 (Uniprot P39900), amino acids 101-268, expressed in and purified from E. coli; human MMP13 (Uniprot P45452), amino acids 103-274, expressed in and purified from E. coli; human MMP14 (Uniprot P50281), amino acids 112-284, expressed in and purified from E. coli; human ADAM17 (Uniprot P78536), amino acids 1-670, expressed in and purified from insect cells (baculovirus expression system); substrate: Ac-C(PT14)-KPLGLWAR-NH2 purchased from Biosyntan (product number 8069); enzyme concentrations: $3 \mathrm{nM}$ (MMP1), $1 \mathrm{nM}$ (MMP2), $3 \mathrm{nM}$ (MMP8), $0.1 \mathrm{nM}$ (MMP9), $0.5 \mathrm{nM}$ (MMP12), $0.13 \mathrm{nM}$ (MMP13), $0.005 \mathrm{nM}$ (MMP14), $30 \mathrm{nM}$ (ADAM17); substrate concentration: $0.8 \mu \mathrm{M}$; assay buffer: $100 \mathrm{mM}$ Tris, $\mathrm{pH}$ 7.4, $100 \mathrm{mM} \mathrm{NaCl}, 10 \mathrm{mM}$ $\mathrm{CaCl} 2,10 \mu \mathrm{M} \mathrm{ZnCl}, 0.075 \%$ (v/v) Brij35.

Cell culture experiments. Cells were maintained in a humidified incubator at $37^{\circ} \mathrm{C}$ and $5 \% \mathrm{CO}_{2}$. HCT116 cells (ATCC \#CCL-247) were grown in McCoy's 5A medium (GIBCO \#16600-082) supplemented with 10\% fetal bovine serum (FBS), TE-1 (RIKEN BioResource Center, \#RCB1894), NCI-H2030 (ATCC \#CRL-591), SU-DHL-1 (DMSZ \#ACC 356), NOMO-1 (HSRRB \#IFO50474) and NCIH196 cells (ATCC, \#CRL-5823) in RPMI-1640 medium (GIBCO\#61870-010) supplemented with $10 \%$ FBS, $10 \mathrm{mM}$ HEPES, $1 \mathrm{mM}$ sodium pyruvate and THP-1 cells (ATCC \#TIB-202) with additional 0.05 mM 2-mercaptoethanol. DMS273 cells (ECACC \#950628) were cultured in Waymouth's MB 752/1 medium (GIBCO\#11220-035) supplemented with 10\% FBS. All cells were negatively tested for mycoplasma contamination either by the vendor or in house. For treatment with compounds, sub-confluent cells were either treated with inhibitors at the indicated concentrations or mock treated with an equivalent amount of DMSO (final content $0.1 \%$ ). If not stated otherwise, cells were harvested after incubation for $16 \mathrm{~h}$ and subjected to SDS-PAGE and western blotting. The RNA interference experiment was performed with CSN5 stealth siRNA (\#HSS116986) and stealth negative control siRNA (\#12935-400) (Invitrogen), which were transfected at $10 \mathrm{nM}$ into HCT116 cells using HiperFect (Qiagen) according to the manufacturer's protocols. Seventy-two hours after transfection, cells were harvested and subjected to SDS-PAGE and western blotting (see Supplementary Fig. 7 for all western blottings performed).

For further analysis, cell lysates were prepared by direct lysis with $2 \times$ Sample buffer (65.8 mM Tris-HCl, pH 6.8, 2.1\% SDS, 26.3\% glycerol, $0.01 \%$ bromophenol blue and $20 \mathrm{mM}$ DTT). Protein lysates from tumour powder were prepared in RIPA buffer (50 mM Tris- $\mathrm{HCl} \mathrm{pH} 8.0,150 \mathrm{mM} \mathrm{NaCl}, 1 \%$ Triton X-100, $2 \mathrm{mM}$ EDTA, $0.5 \%$ sodium deoxycholate and $0.1 \%$ SDS) supplemented with $10 \mathrm{mM}$ $\mathrm{N}$-ethylmaleimide, protease inhibitor and phosphatase inhibitor cocktails (Roche Diagnostics). Cells from longer compound incubations were also lysed in RIPA buffer, which allows the protein concentration to be determined by BCA Protein Assay Kit (Pierce). Proteins were separated by SDS-PAGE using 4-20\% Tris-Glycine Gels (Invitrogen) and subsequently transferred to polyvinylidene difluoride membranes using a Trans-Blot Turbo System (BioRad). Membranes were subsequently blocked with $2 \%$ ECL Prime Blocking Reagent (GE Healthcare) in PBS $0.1 \%$ Tween-20 for $1 \mathrm{~h}$. Primary antibodies were as follows: $\beta$-TrCP (1:1,000; \#11984), Cul4A (1:1,000; \#2699), pIкB $\alpha$ (Ser32, 1:1,000; \#2859), p27 (1:1,000; \#3688), Skp1 (1:1,000; \#2156), Skp2 (1:1,000; \#2652), Wee1 (1:1,000; \#4936), NRF2 (1:1,000; \#12721), pHistone 3 (Ser10, 1:1,000; \#3377), pCHK1 (Ser317, 1:1,000; \#12302), KEAP1 (1:1,000; \#8047), cleaved Caspase3 (1:1,000; \#9661), Caspase3 (1:1,000; \#9665), PARP (1:1,000; \#9542), CDK6 (1:1,000; \# 3136) (Cell Signaling Technology); Cul1 (1:500; \#718700), Cul2 (1:250; \#7001792), Rbx1 (1:300; \#342500) (Invitrogen); Fbxw7 (1:300; \# 55290-1-AP), Fbxo22 (1:500; \#13606-1-AP) (Proteintech); Cul3 (1:1,000; \# A301-109A), CSN5 (1:2,000; \#A300-014A) (Bethyl Laboratories); Fbxo3 (1:300; \#AP9195) (Abgent); p21 (1:500; \#556431) (BD Biosciences); Fbxo30 (1:500; \# H00084085-B01) (Abnova); $\beta$-Actin (1:5,000; \#A5441) (Sigma-Aldrich); Fbxo7 (1:500; \#PA527589) (Pierce). 
Horseradish peroxidase-conjugated secondary antibodies $(1: 3,000)$ were purchased from Promega AG and bound antibody was detected by enhanced chemiluminescence (Pierce).

Cell viability assay. A standardized CellTiter-Glo Assay (Promega \#G7570) based on the quantification of ATP was applied according to the manufacturer's protocol to measure the amount of viable cells in culture. In brief, cells were seeded into 384-well plates at optimal density for each cell line. After $4 \mathrm{~h}$, compounds were added at different concentrations in growth medium and incubated for another $72 \mathrm{~h}$ in a humidifying chamber at $37^{\circ} \mathrm{C}$ and $5 \% \mathrm{CO}_{2}$. Eventually, equal amounts of CellTiter-Glo reagent were added directly to the cells, incubated for $15 \mathrm{~min}$ and luminescence was recorded using PHERAstar plate reader (BMG LABTECH $\mathrm{GmbH})$. The activity of the compounds was calculated relative to vehicle $\left(A_{\max } 0 \%\right)$ and to $1 \mu \mathrm{M}$ bortezomib $\left(A_{\max }-100 \%\right)$. Bortezomib induced quantitative cell death in all cell lines used. $\mathrm{EC}_{50}$ values were calculated from the plot of percentage of inhibition versus inhibitor concentration using the nonlinear regression analysis software Origin 7.5SR6 (OriginLab Corp.).

Xenograft experiment. All animal experiments were approved by the Kantonales Veterinäramt Basel-Stadt and were conducted in accordance with the Eidgenössisches Tierschutzgesetz and the Eidgenössische Tierschutzverordnung. SU-DHL- 1 cells $\left(1 \times 10^{7}\right.$; DSMZ) were implanted subcutaneously into SCID-bg female 7-9-week-old mice (Taconic) and developing tumours were propagated once before subcutaneous transplantation for efficacy studies. Treatment was initiated when tumours reached $150-200 \mathrm{~mm}^{3}$ volume. At this point, animals were randomized into different treatment groups based on similar tumour size and body weight. Randomization was conducted by using an internal computer software (Indigo). CSN5i-3 was formulated in $100 \mathrm{mM}$ citrate buffer pH 3, PEG300, Kolliphor HS15, $1 \mathrm{~N} \mathrm{HCl}$ (56:30:10:4\%w/w). Tumour response is reported as percentage change in tumour volume at the last day of treatment relative to start of treatment. Sample size was $n=4$ (based on $\mathrm{IC}_{50} / \mathrm{EC}_{50}$ data and pharmacokinetic (PK) modelling of the compound) and statistical analysis was performed by comparing the treatment groups $(n=4)$ to the vehicle control group $(n=4)$ at endpoint by Kruskal-Wallis followed by Dunn's post hoc test on $\Delta$ TVol. At day 10 of treatment blood, samples were taken and concentrations of CSN5i-3 were determined at indicated time points post dose using ultra-high-pressure liquid chromatography/tandem MS. At the end of treatment, tumours were excised and snap frozen in liquid nitrogen. Frozen tumours were pulverized using CryoPrep (Covaris Inc.) and protein lysates were prepared from tumour powder for immunoblot analysis.

Data availability. The authors declare that the data supporting the findings of this study are available within the article and its Supplementary Information files. Accession codes: the coordinates for the X-ray structures have been deposited to the Protein Data Bank (PDB) with accession codes 5JOH (complex with CSN5i-1b) and 5JOG (complex with CSN5i-3).

\section{References}

1. Hershko, A., Ciechanover, A. \& Varshavsky, A. Basic medical research award. The ubiquitin system. Nat. Med. 6, 1073-1081 (2000).

2. Coux, O., Tanaka, K. \& Goldberg, A. L. Structure and functions of the $20 \mathrm{~S}$ and 26 S proteasomes. Annu. Rev. Biochem. 65, 801-847 (1996).

3. Komander, D. \& Rape, M. The ubiquitin code. Annu. Rev. Biochem. 81, 203-229 (2012).

4. Deshaies, R. J. \& Joazeiro, C. A. RING domain E3 ubiquitin ligases. Annu. Rev. Biochem. 78, 399-434 (2009).

5. Schulman, B. A. \& Harper, J. W. Ubiquitin-like protein activation by E1 enzymes: the apex for downstream signalling pathways. Nat. Rev. Mol. Cell Biol. 10, 319-331 (2009).

6. Ye, Y. \& Rape, M. Building ubiquitin chains: E2 enzymes at work. Nat. Rev. Mol. Cell Biol. 10, 755-764 (2009).

7. Mani, A. \& Gelmann, E. P. The ubiquitin-proteasome pathway and its role in cancer. J. Clin. Oncol. 23, 4776-4789 (2005).

8. Popovic, D., Vucic, D. \& Dikic, I. Ubiquitination in disease pathogenesis and treatment. Nat. Med. 20, 1242-1253 (2014)

9. Adams, J. \& Kauffman, M. Development of the proteasome inhibitor Velcade (Bortezomib). Cancer Invest. 22, 304-311 (2004).

10. Khan, M. L. \& Stewart, A. K. Carfilzomib: a novel second-generation proteasome inhibitor. Future Oncol. 7, 607-612 (2011).

11. Argyriou, A. A., Cavaletti, G., Bruna, J., Kyritsis, A. P. \& Kalofonos, H. P. Bortezomib-induced peripheral neurotoxicity: an update. Arch. Toxicol. 88, 1669-1679 (2014).

12. Buac, D. et al. From bortezomib to other inhibitors of the proteasome and beyond. Curr. Pharm. Des. 19, 4025-4038 (2013).

13. Nalepa, G., Rolfe, M. \& Harper, J. W. Drug discovery in the ubiquitinproteasome system. Nat. Rev. Drug Discov. 5, 596-613 (2006).

14. Skaar, J. R., Pagan, J. K. \& Pagano, M. SCF ubiquitin ligase-targeted therapies. Nat. Rev. Drug Discov. 13, 889-903 (2014).
15. Li, W et al. Genome-wide and functional annotation of human E3 ubiquitin ligases identifies MULAN, a mitochondrial E3 that regulates the organelle's dynamics and signaling. PLoS ONE 3, e1487 (2008).

16. Petroski, M. D. \& Deshaies, R. J. Function and regulation of cullin-RING ubiquitin ligases. Nat. Rev. Mol. Cell Biol. 6, 9-20 (2005).

17. Soucy, T. A. et al. An inhibitor of NEDD8-activating enzyme as a new approach to treat cancer. Nature 458, 732-736 (2009).

18. Zheng, N. et al. Structure of the Cul1-Rbx1-Skp1-F boxSkp2 SCF ubiquitin ligase complex. Nature 416, 703-709 (2002).

19. Jin, J. et al. Systematic analysis and nomenclature of mammalian F-box proteins. Genes Dev. 18, 2573-2580 (2004).

20. Skaar, J. R., Pagan, J. K. \& Pagano, M. Mechanisms and function of substrate recruitment by F-box proteins. Nat. Rev. Mol. Cell Biol. 14, 369-381 (2013).

21. Bennett, E. J., Rush, J., Gygi, S. P. \& Harper, J. W. Dynamics of cullin-RING ubiquitin ligase network revealed by systematic quantitative proteomics. Cell 143, 951-965 (2010).

22. Deshaies, R. J., Emberley, E. D. \& Saha, A. Control of cullin-ring ubiquitin ligase activity by nedd8. Subcell Biochem. 54, 41-56 (2010).

23. Duda, D. M. et al. Structural regulation of cullin-RING ubiquitin ligase complexes. Curr. Opin. Struct. Biol. 21, 257-264 (2011).

24. Pierce, N. W. et al. Cand1 promotes assembly of new SCF complexes through dynamic exchange of F box proteins. Cell 153, 206-215 (2013).

25. Walden, H., Podgorski, M. S. \& Schulman, B. A. Insights into the ubiquitin transfer cascade from the structure of the activating enzyme for NEDD8. Nature 422, 330-334 (2003).

26. Cope, G. A. \& Deshaies, R. J. COP9 signalosome: a multifunctional regulator of SCF and other cullin-based ubiquitin ligases. Cell 114, 663-671 (2003).

27. Wei, N. \& Deng, X. W. The COP9 signalosome. Annu. Rev. Cell Dev. Biol. 19, 261-286 (2003).

28. Wolf, D. A., Zhou, C. \& Wee, S. The COP9 signalosome: an assembly and maintenance platform for cullin ubiquitin ligases? Nat. Cell Biol. 5, 1029-1033 (2003).

29. Ambroggio, X. I., Rees, D. C. \& Deshaies, R. J. JAMM: a metalloprotease-like zinc site in the proteasome and signalosome. PLoS Biol. 2, E2 (2004).

30. Lingaraju, G. M. et al. Crystal structure of the human COP9 signalosome. Nature 512, 161-165 (2014).

31. Cope, G. A. \& Deshaies, R. J. Targeted silencing of Jab1/Csn5 in human cells downregulates SCF activity through reduction of F-box protein levels. BMC Biochem. 7, 1 (2006).

32. Lee, Y. H. et al. Molecular targeting of CSN5 in human hepatocellular carcinoma: a mechanism of therapeutic response. Oncogene 30, 4175-4184 (2011).

33. Pan, Y. \& Claret, F. X. Targeting Jab1/CSN5 in nasopharyngeal carcinoma. Cancer Lett. 326, 155-160 (2012).

34. Zhong, G., Li, H., Shan, T. \& Zhang, N. CSN5 silencing inhibits invasion and arrests cell cycle progression in human colorectal cancer SW480 and LS174T cells in vitro. Int. J. Clin. Exp. Pathol. 8, 2809-2815 (2015).

35. Lee, M. H., Zhao, R., Phan, L. \& Yeung, S. C. Roles of COP9 signalosome in cancer. Cell Cycle 10, 3057-3066 (2011).

36. Richardson, K. S. \& Zundel, W. The emerging role of the COP9 signalosome in cancer. Mol. Cancer Res. 3, 645-653 (2005).

37. Shackleford, T. J. \& Claret, F. X. JAB1/CSN5: a new player in cell cycle control and cancer. Cell Div. 5, 26 (2010).

38. Cope, G. A. et al. Role of predicted metalloprotease motif of Jab1/Csn5 in cleavage of Nedd8 from Cull. Science 298, 608-611 (2002).

39. Hassiepen, U. et al. A sensitive fluorescence intensity assay for deubiquitinating proteases using ubiquitin-rhodamine110-glycine as substrate. Anal. Biochem. 371, 201-207 (2007).

40. Fischer, E. S. et al. The molecular basis of CRL4DDB2/CSA ubiquitin ligase architecture, targeting, and activation. Cell 147, 1024-1039 (2011).

41. Kikuchi, K., Ishii, N., Asao, H. \& Sugamura, K. Identification of AMSH-LP containing a Jab1/MPN domain metalloenzyme motif. Biochem. Biophys. Res. Commun. 306, 637-643 (2003).

42. Verma, R. et al. Role of Rpn11 metalloprotease in deubiquitination and degradation by the 26S proteasome. Science 298, 611-615 (2002).

43. Oladghaffari, M., Islamian, J. P., Baradaran, B. \& Monfared, A. S. MLN4924 therapy as a novel approach in cancer treatment modalities. J. Chemother. 28, 74-82 (2015).

44. Galan, J. M. \& Peter, M. Ubiquitin-dependent degradation of multiple F-box proteins by an autocatalytic mechanism. Proc. Natl Acad. Sci. USA 96, 9124-9129 (1999).

45. Wirbelauer, C. et al. The F-box protein Skp2 is a ubiquitylation target of a Cul1-based core ubiquitin ligase complex: evidence for a role of Cull in the suppression of Skp2 expression in quiescent fibroblasts. $E M B O J .19$, 5362-5375 (2000).

46. Zhou, P. \& Howley, P. M. Ubiquitination and degradation of the substrate recognition subunits of SCF ubiquitin-protein ligases. Mol. Cell 2, 571-580 (1998). 
47. Barretina, J. et al. The Cancer Cell Line Encyclopedia enables predictive modelling of anticancer drug sensitivity. Nature 483, 603-607 (2012).

48. Meziane, E., Randle, S. J., Nelson, D. E., Lomonosov, M. \& Laman, H. Knockdown of $\mathrm{Fbxo} 7$ reveals its regulatory role in proliferation and differentiation of haematopoietic precursor cells. J. Cell Sci. 124, 2175-2186 (2011).

49. Nelson, D. E., Randle, S. J. \& Laman, H. Beyond ubiquitination: the atypical functions of Fbxo7 and other F-box proteins. Open Biol. 3, 130131 (2013).

50. Epstein, A. L. \& Kaplan, H. S. Biology of the human malignant lymphomas. I. Establishment in continuous cell culture and heterotransplantation of diffuse histiocytic lymphomas. Cancer 34, 1851-1872 (1974).

51. Nagel, S. et al. Amplification at 7q22 targets cyclin-dependent kinase 6 in T-cell lymphoma. Leukemia 22, 387-392 (2008).

52. Moreau, P. et al. Proteasome inhibitors in multiple myeloma: 10 years later. Blood 120, 947-959 (2012).

53. Robak, T. Bortezomib in the treatment of mantle cell lymphoma. Future Oncol. 11, 2807-2818 (2015).

54. Enchev, R. I., Schulman, B. A. \& Peter, M. Protein neddylation: beyond cullin-RING ligases. Nat. Rev. Mol. Cell Biol. 16, 30-44 (2015).

55. Cooper, E. M. et al. K63-specific deubiquitination by two JAMM/MPN + complexes: BRISC-associated Brcc36 and proteasomal Poh1. EMBO J. 28, 621-631 (2009).

56. Zheng, H. et al. A BRISC-SHMT complex deubiquitinates IFNAR1 and regulates interferon responses. Cell Rep. 5, 180-193 (2013).

57. Py, B. F., Kim, M. S., Vakifahmetoglu-Norberg, H. \& Yuan, J. Deubiquitination of NLRP3 by BRCC3 critically regulates inflammasome activity. Mol. Cell 49, 331-338 (2013).

58. Kroemer, M., Dreyer, M. K. \& Wendt, K. U. APRV - a program for automated data processing, refinement and visualization. Acta. Crystallogr. D Biol. Crystallogr. 60, 1679-1682 (2004).

59. McCoy, A. J. et al. Phaser crystallographic software. J. Appl. Crystallogr. 40, 658-674 (2007)

60. Echalier, A. et al. Insights into the regulation of the human COP9 signalosome catalytic subunit, CSN5/Jab1. Proc. Natl Acad. Sci. USA 110, 1273-1278 (2013).

61. Emsley, P. \& Cowtan, K. Coot: model-building tools for molecular graphics. Acta Crystallogr. D Biol. Crystallogr. 60, 2126-2132 (2004).

\section{Acknowledgements}

We thank N. Thomae and M. Lingaraju for the baculoviruses used for the generation of $\mathrm{CSN}$ and Cul4A complexes and protocols for their expression and purification. We are grateful to Keith Pfister, Adelaide Druet, Celine Dentel and Hanneke Jansen for support with the synthesis and modelling of CSN5 inhibitors; Claude Logel and Ingrid Bechtold for help with protein production; Christelle Arnold for assistance with the automation of the cell assay; the NIBR CLiP team for profiling compounds on the cancer cell panel; Sandrine Desrayaud, Ralf Endres, Peter Wipfli, Alexandra Buhles, Flavia Reimann, Laetitia Martinuzzi and Dario Sterker for support with the xenograft and pharmacokinetic study; William Sellers, Emma Lees, Michael Dillon and Sylvain Cottens for fruitful discussions and advice on the project.

\section{Author contributions}

B.M. and A.B.J. initiated the project. J.E. supervised the project and contributed to the design of experiments for compound optimization. A.S. performed the cell culture experiments and cellular assays, and helped with the preparation of the figures. E.A. and J.Q. generated and optimized the CSN5 inhibitors with support from R.S., M.R. and C.W carried out the crystallographic studies and M.S. carried out the modelling. U.H. and M.J. ran the biochemical assays. R.A. produced the proteins and wrote on the manuscript. A.W. and M.K. performed the xenograft study and the pharmacokinetics analysis. B.M. led the project, designed experiments, prepared the figures and wrote the manuscript together with J.E. All authors discussed the results and commented on the manuscript.

\section{Additional information}

Supplementary Information accompanies this paper at http://www.nature.com/ naturecommunications

Competing financial interests: The authors declare conflicting financial interest; authors are employees of Novartis Pharma AG.

Reprints and permission information is available online at http://npg.nature.com/ reprintsandpermissions/

How to cite this article: Schlierf, A. et al. Targeted inhibition of the COP9 signalosome for treatment of cancer. Nat. Commun. 7, 13166 doi: 10.1038/ncomms13166 (2016)

(c) (i) This work is licensed under a Creative Commons Attribution 4.0 International License. The images or other third party material in this article are included in the article's Creative Commons license, unless indicated otherwise in the credit line; if the material is not included under the Creative Commons license, users will need to obtain permission from the license holder to reproduce the material. To view a copy of this license, visit http://creativecommons.org/licenses/by/4.0/

(C) The Author(s) 2016 